\title{
Future of Prostate Biopsy: Who Will Get It and How?
}

\author{
Tine Hajdinjak \\ Center UROL Maribor \\ Department of Surgery, General Hospital Murska Sobota \\ Medical Faculty, University of Maribor \\ Slovenia
}

\section{Introduction}

Prostate biopsy is a motor, driving force and entrance ticket for dealing with parade discipline in urology of recent years - prostate cancer. Therefore it receives a lot of attention and standard techniques are constantly challenged by new developments. Enormous amount of literature seem to have addressed all possible aspects regarding prostate biopsy. This chapter focuses less on historical overview but mainly on recent developments, controversies and questions.

Prostate cancer has already become leading cancer among males in developed world (Jemal et al., 2011), second reason for death due to cancer among men in US (Jemal et al., 2010) and third in Europe (Malvezzi et al., 2011). Future is looking even more serious - numbers are expected to rise much further, as recently predicted in Canadian forecast analysis (Quon et al, 2011). The authors claim expected estimates of increase in prostate cancer cases should not be limited only to aging of population, which is huge itself and is expected to cause $39 \%$ increase in prostate cancer cases. At least three further factors should be taken into account. First and most important is lowering of PSA threshold for biopsy. It seems the move of decreasing PSA cutoff from 4 to 2.5 is getting from university centers to every urologist's and generalist's office (this is especially important as they are the ones who pick and refer patients to urologists for biopsy). Increase in number of people, referred to biopsy for this reason is estimated to be much greater compared to aging of population and may increase prostate cancer incidence by $200 \%$. If it will increase prostate cancer incidence by $200 \%$, increase in number of biopsies should be disproportionally higher, as biopsies have lower yield for this new target population with PSA values between 2.5 and 4. PSA screening is creating at present a lot of debate, it is a very hot topic and there are very strong opponents and supporters. Introduction of formal screening would of course increase burden of cancer and burden of biopsy. It is at present unlikely to happen, probably because people who decide on health policies and their advisers do not meet, treat and care for people with advanced prostate cancer. But, call it case finding or however one prefers, a "non-formal" screening programs are actually already available in many health systems, not only in selected first adopters, like Tyrol in Austria (Oberaigner et al., 2006), but also for example in Slovenia, where every general practitioner has available extra funds for PSA measurement on all of his male patients, every two years. Extent of "nonformal" screening programs can be seen from well-known PLCO trial, where control, 
supposedly non-screened arm had 50\% screening in comparison to intervention arm, supposedly "screened", where the rate was approximately 85\% (Andriole et al., 2009). Some do not believe into usefulness of screening (Miettinen, 2010) and results of studies, which clearly show improved survival and necessity for screening, for example of European Randomized Trial of Screening for Prostate Cancer (Schröder et al., 2009). Despite those doubts, screening in one way or another is in fact increasingly taking place in every-day life. Further increase in screening is expected because recent analyzes of prostate screening studies seem to greatly reduce predicted numbers needed to screen and numbers needed to treat to save a life in prostate cancer and dispel previous doubts about usefulness of screening (Crawford et al., 2011) and treatment (Bill-Axelson et al., 2011).

Last reason for estimation of huge increase in prostate cancer cases expected in the next decade is stated (Quon et al., 2011) as "improved sensitivity of prostate biopsy". Will this really happen? This review will summarize some of the present developments in this field. If this is really the case, it may be at least one good sign, sign of relief: with improved biopsy specificity, number of repeat biopsies, which at present already represent significant burden and may also represent group of patients with higher risk for biopsy-related complications, may decrease.

Prostate biopsy aims to detect prostate cancer with as little problems and sequela as possible. Further, it aims to predict prognosis of detected cancer, therefore sampling must not only take any cancer, but representative cancer tissue samples from possibly all cancer focuses in the prostate. Third goal of modern prostate biopsy is to guide targeted therapy, which is expected to rise with increased number of lower stage cancers detected.

\section{Selection of biopsy candidates}

Only main criteria, which are in clinical use or are available and may be used in Europe in 2011 are included here and they are: 3 PSA's (total, free and -2proPSA), urine marker (PCA3), race, family history, previous biopsy technique and result, age and life expectancy.

There are markers, which were proposed and also used in the past, but are now outdated, like cPSA and other PSA's, not mentioned above. There are markers, which may become very useful in the future, but are at present not ready yet (for example SNP's and other genetic data or new urine markers, which may use advantage of being excreted and therefore no aggressive rectal prostate massage would be necessary (Pandha et al., 2011)). Should we really biopsy all men with PSA above 2.5? Obviously we do not want to do that. It remains unresolved task, how should we select between those who would benefit from biopsy even earlier, at PSA 1, from those who do not need biopsy at PSA 10.

\subsection{PSA's}

Prostate specific antigen, during history of its discovery named with other names, for example semenogelase, is an androgen-regulated serine protease (EC 3.4.21.77), human tissue kallikrein 3 (Balk et al, 2003). Gene is located on 19q13.4. Mainly it is produced in secretory epithelial cells in prostate acini and ducts and secreted into lumen. Its function is in ejaculate liquefaction.

PSA is expressed in preproPSA form (17 aminoacid leading peptide), excreted into prostate lumen as proPSA (7 aminoacid propeptide on N-terminal) and activated by trypsine-like human kallikrein 2 (hK2), which is expressed on prostate secretory epithelial cells (Balk et.al, 2003). ProPSA can undergo cleavage at position -7, removing 7 aminoacid propeptide to form active PSA. ProPSA cleavage can also occur at positions -5 or -2 . Those PSA isoforms 
are not catalytically active. Active PSA in part undergoes further degradation/internal cleavage by different proteases, thereby also forming inactive PSA. In seminal plasma approximately $30 \%$ of PSA is in active form. Remaining PSA represents different forms of inactive PSA. Some PSA (all forms) leaks to circulation and can be measured in serum. Active form of PSA in serum binds (complexes) to protease inhibitors, mostly to alpha1antichymotrypsin (ACT). It represents main part of total serum PSA (70-90\%) and can be measured as cPSA. Catalytically inactive PSA forms circulate freely in serum as they are not complexed to ACT or other inhibitors. This fraction represents main result of free PSA assay. Antibodies were also developed for measuring serum concentrations of specific PSA isoforms, for example [-5]pro PSA and [-2]proPSA. Assays which measure total PSA aim at detecting all isoforms, active (complexed) and inactive PSA.

As prostate cancer characteristic is disruption of basal cell layer and basement membrane, this allows increased amount of PSA and its isoforms to enter circulation (Balk et al, 2003). Free PSA fraction is decreased in serum of cancer patients. It is hypothesized there is relatively less free PSA in serum in cancer patients because more PSA enters circulation directly and complexes immediately to protease inhibitors. As there is less exposure of PSA to luminal and seminal fluid proteases, there is less chance for inactivating and producing inactive, free PSA. ProPSA isoforms are increased in serum of prostate cancer patients. Two hypotheses aim to explain this. One believes there is decreased cleavage of proPSA by hK2 in prostate cancer tissue (Balk et al., 2003). Other hypothesis believes proPSA isoforms are increased in cancer as a result of increased proPSA production from benign looking cancer associated areas in prostate gland (Makarov et al., 2009).

Higher serum PSA values were related to prostate cancer in 1980-ties. Hybritech, first commercial PSA measurement kit manufacturer, identified in a small study in 1986 in their sample $99 \%$ of tested men (different ages) had PSA below 4 and suggested this value as a cut-off. With this in hand, Catalona conducted a trial and published in 1991: 8\% of tested men (mean age 68) had PSA values above 4, 22\% of those with PSA between 4 and 10 had prostate cancer detected on sextant biopsy (and 67\% among those with PSA above 10). Biopsy was performed using 18G needle. PSA was independent prognostic factor and positive DRE increased chance of positive biopsy (Catalona et al., 1991). 20 years later - we made a progress - now we do 12 core biopsies, use PSA cut-off 2.5 and use some other PSA derivatives to help in decisions. This modifies our outcomes a few percentages here and there, but main achievement, decrease in mortality due to prostate cancer, which was, after two decades of doubt, finally recently confirmed by a few large independent trials from both US and EU (see Introduction), was a result of a twenty years old approach, which is, with all its drawbacks and deficiencies, still valid and widely practiced around the world.

Inadequacy of PSA cut-off value of 4 was in depth explained by publication of results of control biopsies in prostate cancer prevention trial (Thompson et al., 2004). They found, among men in age range 62 to 91 , median $69,6.6 \%$ of cancers among those with PSA 0.5 or less and $12.5 \%$ among them with Gleason 7 or more $(=0.8 \%$ of all men with median age 69 with PSA below 0.6 had important cancer). Among men with PSA of 1.1 to 2.0, cancer was found in $10 \%$ and $10 \%$ of those had Gleason 7 or more $(=1 \%$ of all men with PSA between 1 and 2, median age 69, had Gleason 7 or higher prostate cancer). For PSA 2-3, the percentage of Gleason 7 or more among all tested was $4.6 \%$ and for PSA 3-4 it was $6.7 \%$. Those numbers were found in a prescreened population and with sextant biopsy. Now it is believed those numbers are still accurate for overall cancer presence, but for Gleason 7 or higher cancers in general referral population, real numbers are about twice those estimates. Several thoughts 
follow from this data. One is related to high percentage of high grade cancers in population with median age 69 and relatively low PSA values. Once upon a time, it was suggested we should not measure PSA in men above 70 . Should we now turn this completely around and biopsy all men with life expectancy of 10 yeas or more at the age of 70 irrespectively of their PSA? Or should we use other tests, like PSA isoforms derivatives?

Free PSA is measured to calculate fraction towards total PSA value, which is expressed as percentage. In PSA ranges between 4 and 10, with \% free PSA below 10\%, probability for biopsy detected prostate cancer in DRE negative patients was $56 \%$ and with $\%$ free PSA above $25 \%$ probability of cancer was only $8 \%$. In PSA range between 2.5 and 4 , with $\%$ free PSA below $10 \%$, probability of cancer was $46 \%$ and with $\%$ free PSA above $20 \%$ probability of cancer was $8 \%$ (Catalona et al., 1998).

[-2]proPSA or p2PSA is new kid on the block, which is not yet universally available or accepted. It seems it will become next widely used PSA derivative, which is also used together with free PSA value (p2PSA/freePSA) or together with total and free PSA as value, calculated as p2PSA/freePSA times square root of total PSA and proprietary named by Beckman Coulter (Brea, California, USA) as PHI - prostate health index. Cut-off values for biopsy decisions using \%p2PSA (p2PSA/free PSA) and PHI are not yet universally accepted and differ with regard to free PSA and total PSA calibration method (Hybritech or WHO), but it seems PHI values above 40 or 45 indicate high and below 21 low risk of prostate cancer. PHI of more than 48.5 was reported as $43 \%$ specific at $90 \%$ sensitive for detecting prostate cancer at initial prostate biopsy (Guazzoni et al., 2011). Another study reported PHI values above 34.2 to show increased probability for high risk disease (Isharwal et al., 2011). PHI was shown to indicate development of prostate cancer years before biopsy and correlated well with grade of future prostate cancer (Bektic et al., 2010). On negative side, using p2PSA compared to free PSA using ROC curves at area of high sensitivity (if we are to find cancer), increase in performance may seem marginal.

PSA density and different variants (PSA density of transitional zone etc), calculated from total PSA value and measurement of prostate volume using transrectal ultrasound, were in the past extensively evaluated. Drawback is variability of prostate volume measurements, need for this additional investigation and low sensitivity (Pepe et al., 2009). One example of cutoff value was density above $0.15 \mathrm{ng} / \mathrm{ml}$ PSA / $\mathrm{ml}$ prostate volume indicating higher risk of cancer. It may represent additional useful piece of information, also for example regarding prediction of disease course for patients on watchful waiting (Kotb et. al, 2011).

PSA velocity was in recent years proposed as another potentially helpful tool in picking cancers or high-risk cancers. Cutoff value of $0.35 \mathrm{ng} / \mathrm{ml} /$ year was proposed when total PSA values are less than 4 . This may need adjustment for race (Tang et al., 2011). Although some doubts about value of PSA velocity in biopsy decisions were posed from analysis of PCPT trial data (Vickers et al., 2011), there are suggestions a lot of clinically important cancers in younger men may be detected by regularly and meticulously following and analyzing sequential PSA values (Bektic et al., 2011).

PSA values increase with age due to BPH. This became known early after PSA test introduction and "age-specific" PSA values were suggested. For Caucasian Americans, median, $75^{\text {th }}$ and $95^{\text {th }}$ percentiles of PSA were for age group 40-49 - 0.7, 1.0 and 2.1, for 50-59 age group 1.0, 1.6 and 3.6, for 60-69 age group 1.4, 2.5 and 4.3, for 70-79 decade 1.8, 3.5 and 5.8 (Morgan et al., 1996). One approach of integrating age specific PSA values in prostate biopsy decisions may be using as cutoff half of age-specific 95th percentile PSA value together with \% free PSA below 18\%, which was in part used in Innsbruck (Tyrol, Austria). 
High increase of PSA with infection or any irritation of prostate is well known and sometimes antibiotic or anti-inflammatory treatment is suggested and repeat measurement. PSA decreases in high body-mass index-correction and decreased of cutoff values may be needed (Pater et al., 2011). Diseases (liver cirrhosis) and medications (NSAID's, thiazides and statins) may also decrease PSA values (Nieder et al., 2011). If using free PSA values as trigger for biopsy decisions, it may be important to note that use of herbal products, like Serenoa repens, may (artifically?) increase free PSA values.

\subsection{Age and life expectancy}

Risk of prostate cancer significantly increases with age. Age is significant independent predictor of high risk prostate cancer. Although we need age as a criterion (we do not start to think about prostate cancer before age of 40 or 35), it is clear age could not be the only factor which would preclude decisions about PSA measurement, digital rectal exam and biopsy. Age is only one parameter in estimation of life expectancy. Life expectancy, not age, is crucial factor in decisions regarding prostate cancer screening interventions. Age does increase probability of cancer and cancer related death and therefore higher age - for example 75 years or more (with additional criterion of more than 10 years life expectancy) means strong indication in-favor of PSA screening and prostate biopsy. It is true that not all men at age 75 or more have more than 10 years of life expectancy, but significant number have and for them, prostate cancer screening is most useful and fruit bearing (much higher yield compared to younger men). This thinking is in strong contrast to past belief (and even now supported by some outdated recommendations of non-urological organizations), when PSA testing was not recommended generally for all older men.

\subsection{Digital rectal exam}

Digital rectal exam remains important part of prostate evaluation (Gosselaar et al., 2008). Although still on occasion declined by a patient and despite hopes PSA or any other method would completely replace it (Schroder et al., 1998), one still finds from time to time a case, where PSA is low and DRE is suspicious. For such a patient, next year, when PSA has increased, may be (and cases were confirmed it was) too late. Although after many suspicious DRE's biopsy comes negative, we are more and more aware of the fact that prostate cancer may progress without PSA increase. DRE can estimate sphincter tone, in a way prepare patient for biopsy, if needed, on occasion register some other, non-urological pathology and appreciate prostate size, which may give different dimension compared to ultrasound impression. DRE is necessary for sampling prostate cells in post-massage urine at present for PCA3 only, but in the future maybe also for other markers. DRE is necessary for clinical staging of prostate cancer. DRE is limited, it can not palpate whole gland, but at present it is here to stay (Yossepowitch, 2008).

\subsection{PCA3}

Comparison of mRNA expression patterns of prostate cancer and benign tissues identified significantly different expression of non-coding mRNA sequence, first called DD3 (Bussemakers et al., 1999) and later renamed PCA3. Technology (a variant of quantitative nucleic acid amplification test) was developed to identify very minute amounts of PCA3 mRNA from prostate cells shed in prostate urethra after prostatic massage and washed out immediately in first voided urine portion. Its estimated amount (number of copies) is 
normalized to estimated number of PSA mRNA copies in the same sample and multiplied by 1000, resulting in PCA3 score. Test is known as Progensa PCA3 Assay (Gen-Probe Inc, San Diego, USA). Higher PCA3 score values indicate greater risk of presence of prostate cancer. Values from approximately 4 to 125 can be obtained, 35 being most often suggested cut-off, which, according to package insert has $53 \%$ sensitivity and $74 \%$ specificity for detection of prostate cancer on subsequent biopsy. Other cut-off opinions are continuously evaluated (Auprich et al., 2011). Although PCA3 mRNA theoretically could be measured in urine also with standard molecular-medicine techniques, which first isolate mRNA from cells in the sample and then perform RT-PCR, is this, due to very small amounts of PCA3 mRNA, very difficult and inconsistent, therefore dedicated patented method from Gen-Probe which uses direct amplification and avoids isolation step, has become standard.

PCA3 use was suggested and marketed as help in biopsy decisions in previously negative prostate biopsies, in men with other risk factors (family history) and normal PSA values, in men with big prostates or other prostatic conditions where it is unclear whether high PSA is driven by cancer or other factor and in men on watchful waiting where high PCA3 score may indicate higher burden of disease.

Use of consecutive PCA3 tests for follow up of biopsy candidates or men on watchful waiting was questioned due to high variability of results, if test is repeated in the same individual with low risk disease (Shikanov et al., 2011).

Pre-biopsy PCA3 test results were evaluated together with PSA in relation to tumor characteristics in radical prostatectomy specimens (Vlaeminck-Guillem et al., 2011). It was found PCA3 score did not correlate with PSA and prostate volume. PCA3 score was also not related to Gleason score and pT stage. PCA3 did correlate with total tumor volume and index lesion volume. Further, multifocality was significantly correlated with PCA3. PCA3 expression can be identified on malignant and benign prostate tissue samples, only quantity varies (Quiles et al., 2011).

PCA3 test is, with many mentioned drawbacks and despite its high price, widely marketed and used in USA and EU. It seems sometimes may help in biopsy related decisions, but its role at present is still evolving.

\subsection{Family history, race, previous biopsy result}

Theoretically one may differentiate between familial (unpredictable clustering of disease in a family, slightly increased risk for offspring) and hereditary cancer (strong clustering pattern consistent with passage of a susceptibility gene via Mendelian inheritance) (Potter \& Partin, 2000). Criteria for hereditary prostate cancer would be three or more first-degree relatives had prostate cancer, three successive generations had prostate cancer and where two relatives were affected at or before age 55. Despite identification of such families, their investigation has not resulted in such successful discoveries as in colon, ovary and breast cancers. In those classic hereditary cancers presence of a certain identifiable mutation with high probability predicts development of cancer in all affected offspring, which has resulted in formal screening programs for affected families and preventive surgery at early age. This is at present not known in prostate cancer.

Familial history of prostate cancer increases risk. In a meta-analysis brother with prostate cancer increases risk 3.3 times, father 2.2 times, two first-degree relatives 5 times (Zeegers et al., 2003). 
It is accepted increased risk due to family history should result in earlier start of screening (at age 40 or 35). Some risk calculators do use family history information to modify risk estimation (increased risk for presence of cancer in first degree relatives, this means father, brother or son), which may influence biopsy decision, if based on calculated risk. But apart from this, it does not tell us anything - PSA and other cut-offs for decision about biopsy are the same as in men without family history. Also procedures for biopsy, treatment and also treatment outcomes are the same between familial, hereditary and sporadic prostate cancer. There is no known $100 \%$ risk situations, which would provoke preventive removal of prostate, as is known for breast cancer, although people sometimes do ask for this.

Recent research focused also on risk of prostate cancer in men whose family members have other forms of cancer. Men with first degree relative with breast cancer, who developed breast cancer at the age 35 or earlier, are at significantly increased risk of prostate cancer $(5$ to 18 times in case of BRCA mutation) (Dite et al., 2010). Other cancers in family may also increase risk of prostate cancer (Izmirlian et al., 2011).

Race is used in many prostate cancer risk calculators - African American race increases risk compared to Caucasians, Hispanic or Asian have decreased risk. But, the same as for family history, apart from earlier start of screening or a little different risk estimates from calculators, there are no other practical consequences of this fact at present.

Previous negative biopsy decreases risk of positive subsequent biopsy. There are, however, two findings, which differ: PIN (=HGPIN - high grade prostatic intraepithelial neoplasia, low grade PIN was abandoned) and ASAP (atypical small acinar proliferation). HGPIN is most probable precursor of prostate cancer. There are structurally benign ducts and acini with abnormal secretory cells with prominent nucleoli (Schoenfield et al., 2007). HGPIN is a histological entity in itself, it is not cancer. ASAP indicates finding of small focus of structure in a 2-dimensional view, which is not large enough to satisfy criteria for cancer. It may represent only specific cut of top of benign acinus or PIN. One may define different characteristics under ASAP category, like adenosis, intraductal hyperplasia... which have in common that pathologist can not say for certain, whether they represent cancer or not. As ASAP may represent cancer, is was identified as predictor of positive repeat biopsy. Identification of multiple HGPIN in a biopsy specimen was also identified as predictor of positive repeat biopsy (Akhavan et al., 2007). Therefore, ASAP and HGPIN require consideration about repeat biopsies. ASAP may require immediate scheduling for repeat biopsy. HGPIN requires careful follow up and in most cases other criteria (PSA increase) cause repeat biopsy sooner or later (for example in 1-2 years time).

\subsection{Risk based strategies}

Different nomograms were developed, which can predict risk of positive biopsy. They take into account risk for age, family history, race, PSA and free PSA, digital rectal exam and some also for body mass index and even new decision aids, for example PCA3 and PHI.

Nomograms have introduced new dimension in patient-physician pre-biopsy discussion. Need for individual's risk adjustment is illustrated by cardiology example. Do general practitioners and cardiologists decide whether one needs aspirin or statin on a single total cholesterol measurement (for example with result of $5.3 \mathrm{mmol} / \mathrm{L}$, just above normal)? No. They measure HDL, LDL cholesterol, they ask for age, gender, blood pressure, smoking history. They consult nomograms and then decide whether statin drug is necessary (and reimbursed) or not. But urologists were dependent on a single PSA value? This has changed 
with risk calculators availability. Using single PSA cutoff value would be the same as claiming for a man, who runs marathon, has normal blood pressure, normal BMI, is a non-smoker, his parents lived till age 100 and has cholesterol of $5.3 \mathrm{mmol} / \mathrm{L}-$ to be at high risk for cardiac event because his cholesterol is elevated (above 5.2). Using single PSA value for biopsy decision would be the same as claiming for an overweight (BMI 30), sedentary man, heavy smoker, on three anti-hypertensive medications whose parents both died of cardiac event, because his cholesterol is $5.1 \mathrm{mmol} / \mathrm{L}$ (just normal) - not to be at risk for cardiac event. Everyone can clearly see ridiculosity, absurdity of such approach in cardiology - but we in urology use PSA as single dichotomous variable in our prostate biopsy decisions?! Risk calculators allow us to tell men with any PSA value their individual chances for biopsy outcome. Calculators report risk for high grade (Gleason 7 or more) and overall cancer probability. For example if calculator predicts $6 \%$ chance of significant prostate cancer (Gleason 7 or more) and $26 \%$ of overall cancer risk, we should tell patient his chance of being without cancer at present is approximately $74 \%$ (100-26), he has $6 \%$ chance of finding important high risk cancer and he has approximately $20 \%$ (26-6) chance biopsy would find cancer which may not be clinically important at present (but maybe in the future) and we would have to deal with this. If we explain this way, most men can and do take their own decision, whatever it is (to proceed with biopsy or continue PSA follow up).

Using risk calculators often surprises us with values one would not expect. For example use Sunnybroke Prostate risk calculator (see below) and take 75 years old healthy Caucasian male with PSA of 3.9, \% free PSA 22\%, IPSS 9, in a good health (for example upper $25 \%$ of his generation), no family history for prostate cancer and negative DRE. He has more than 15 years of life expectancy, 39\% risk of prostate cancer and 20\% risk of having at present high grade prostate cancer (Gleason 7 or more). 20\% risk of high grade cancer and more than 15 years of life expectancy - would you suggest a biopsy?

At present (june 2011), one of the most modern (can take into account PCA3, p2PSA...) prebiopsy nomograms is available from UT Health Science Center, San Antonio, head Ian Thompson (http://deb.uthscsa.edu/URORiskCalc/Pages/calcs.jsp). Opponents of his calculator state it has good estimation of overall cancer risk, but underestimates high risk cancers. Large urology collection of nomograms, also many pre-biopsy nomograms including estimation of biopsy risks, are available from Pierre Karakiewicz, Cancer Prognostics and Health Outcomes Unit from University of Montreal Health Centre, Canada (www.nomograms.org). Calculators derived from European Randomized study of Screening for Prostate Cancer (Fritz Schroeder) are available at SWOP Prostate Cancer Research Fundation: http://www.prostatecancer-riskcalculator.com/via.html. Useful, simple and modern (more accurate high risk cancers estimation) pre-biopsy nomogram is available from SunnyBrook Health Sciences Centre, Toronto: http://sunnybrook.ca/ content $/$ ?page $=$ OCC_prostateCalc.

Different nonograms, for example taking into account 3D biopsy approach (Sakura et al., 2011) are being developed and published constantly. Also, comparisons (Oliveira et al., 2011) and evaluations (Ngo et al., 2011) are permanently performed and published. When using nomograms, one should be aware of their limitations (Vickers \& Cronin, 2010).

NCCN guidelines on prostate cancer early detection not require nomogram use, follow in part risk adapted approach, cover most "before biopsy" issues, are regularly updated and modern. They are available freely after registration from www.nccn.org. 


\section{Methods of biopsy}

Prostate cancer was in the past diagnosed most often using histology from transurethral resection, which was performed for local complications of prostate cancer or merely $\mathrm{BPH}$. As it became clear such diagnosis is most often too late, makes subsequent radical surgical treatment more difficult and as PSA become available, biopsy had become diagnostic method of choice. At first, it was finger guided, blind. With development of transrectal ultrasound (trus - transrectal ultrasound guided prostate biopsy) and coupling it to 18G needle, Pandora box of prostate cancer was opened.

\subsection{Transrectal or transperineal approach?}

Most prostate biopsies around the world are performed transrectally, as this naturally developed from transrectal finger guided approach, is cheaper, simpler, does not need any analgesia or anaesthesia (although it is highly recommended, see section 4.3). Transperineal approach does need at least local anaesthesia. On same occasions, like post surgical amputation of the rectum, if it is sutured, transperineal biopsy (or transgluteal) may be the only way. However, such biopsy is guided by US probe on the perineum or in the urethra or more often by CT or MRI, which is not the way transperineal biopsy is performed regularly. Regular transperineal biopsy is performed using probe in the rectum and needle is advanced through the skin above rectal opening. Transperineal approach has similarity with the way some treatments are performed (brachytherapy...). Treatment templates may be used for biopsy which may guide biopsy needle to a specific part of prostate, which is seen as potentially more effective and with better gain. Recently, stereotactic templates (even motorized and computer guided) have become available also for transrectal prostate sampling - mechanically assisted 3D TRUS guided biopsy system (Megwalu et al., 2008). Supporters of transperineal approach suggest transperineally apical and anterior parts of the prostate may be better accessed compared to transrectal approach. For those reasons, studies were designed to compare yields of transrectal versus transperineal biopsy approach in primary 12-core and saturation 20-core schemes (Hara et al., 2008; Abdollah et al., 2011). Those studies uniformly showed no difference in cancer yields. However, this has not convinced proponents of transperineal approach. In regions, where transperineal approach was used routinely and claimed to be better compared to transrectal (for example some parts of Italy), they are only lately discovering prostate biopsy with end-fire probe (Galosi et al., 2010). Due to technical development of ultrasound equipment, some manufacturers (also very respectful one), were using side-fire probe with needle "through-the-probe" technology. This was proved to be inferior (Chin et al., 2009) in comparison to end-fire biopsy approach (see below). Therefore comparison of perineal to side-fire transrectal approach is not appropriate. Combination of transrectal and transperineal approach has also been used and described, aiming at gaining best from both approaches and maximizing cancer detection rate (Kawakami et al., 2007).

Transrectal approach is recommended for routine primary and also saturation prostate biopsy. On rare occasions, where stereotactic guidance may be needed, decision on approach depends on availability of equipment. At present, equipment for transperineal stereotactic approach is more often available and more widespread, due to its use for brachytherapy (and different other new experimental approaches, such as cryotherapy or photodynamic therapy), compared to new and only limited availability of transrectal 
computer and motor guided tools for prostate biopsy. Therefore, transperineal biopsy may be method of choice in selected cases.

\subsection{Transrectal ultrasound probe}

After analogue ultrasound probes have settled to history, electronic probes prevailed. Rotating mechanical sector probes have not gained popularity in the past. Present standard is electronic multi-element transducer - array. They come in two configurations. Side-fire probes have longitudinal transducer and take biopsies in longitudinal sections - sagittal plane, while endfire probes have curved array detector and allow biopsies to be taken also in transverse plane. In the past, Bruel and Kjaer and Kretz offered for prostate biopsy primarily side-fire probes and this was subjectively seen as better approach compared to end-fire probes (vaginal probes), used "secondarily" also for prostate biopsies. However, end-fire proponents build hypothesis better detection rate to be expected with end-fire sampling in transverse plane due to ability to direct needle more towards lateral part of the peripheral zone, where most tumors arise. This hypothesis was at first tested and confirmed for sextant biopsy in PSA range 4-10 (Paul et al., 2004). This issue was challenged again in 2009, hypothesising end-fire probe has more oblique angled trajectory allowing better peripheral sampling (Ching et al., 2009). To reach anterior gland and apex in longitudinal plane, side-fire probe should be turned a lot and moved in a way which often causes pain as moves point of entry of the needle below dentate line of the rectum. End-fire probe allows better manipulation and targeting desired areas of prostate. Hypothesis was confirmed in their study, finding significantly better detection rate overall in the end-fire group compared to side-fire group and better detection in side-fire group for biopsies with more than 8 cores (8-12, 13-19 and 20 and more) and all PSA ranges (below 2.5, 2.5-4, 4-10 and more than 10) (Ching et al., 2009)

Later, side-fire probes were often bi-planar, therefore allowing better orientation in the prostate, if one views it in two planes and offering choice between end-fire or side-fire biopsy guide. At present, interest has moved from purely end-fire or side-fire biopsy towards combined biopsy opinions and probe designs are now aiming further at 3-plane, 3D imaging and computer guidance... Biplanar probes have become standard equipment also because linear longitudinal array on the probe is necessary for transperineal prostate procedures guidance, while end-fire part is used for standard transrectal biopsy. Ideally, one should have the ability to use biplanar probe, but probably prefer end-fire setting for taking most biopsy cores.

As history is repeating and revealing again in many aspects of human life, new TargetScan device (Envisioneering Medical Technologies, St. Louis, MO, USA) uses mechanical sector probe with single rotating element, applying it in "side-fire" configuration, but with needle, which bends, thus overcoming drawbacks from side-fire systems (Taneja, 2006).

\subsection{Biopsy needle}

Form, length, thickness, shape of biopsy needle, as everything regarding prostate biopsy, is being constantly challenged. It seems at present thickness of the needle is settled to 18G, needles are side-notch, true-cut, straight with stroke length of $22 \mathrm{~mm}$.

But it was not always so - aspiration biopsy (cytological biopsy) was around and well not so many years ago (Gustafsson et al., 1990). Length of the needle may not seem important at first sight, but for systematic sampling of all areas of big prostates, standard needle length may become limiting factor, as it may simply not be possible to advance needle from biopsy guide into the prostate enough to get sampling of all desired areas in a big or a bit 
differently formed prostate. For example, TargetScan (Envisoneering) declares needle movement of $2.2 \mathrm{~cm}$ (standard for most biopsy guns, but not all) and possibility of needle protruding $2 \mathrm{~cm}$ from tip of biopsy guide before firing - together $42 \mathrm{~mm}$ of needle penetration. This is a description of a dedicated "robotic" system. In every day life, where ultrasound system and needle guide are one thing, hospital's supply for needles another and hospital's selection of biopsy-guns third issue, this should be considered, measured and perhaps some longer needles acquired for bigger prostates. Many other variants of needle characteristics were evaluated. Regarding stroke length, $33 \mathrm{~mm}$ end-cut was proposed (Dogan et al., 2005) by some, others proposed $29 \mathrm{~mm}$ side-notch instead of $22 \mathrm{~mm}$ (Fink et al., 2005). It is obvious longer is better and at least $22 \mathrm{~mm}$ should be used instead of old $15 \mathrm{~mm}$, which was used at introduction of now obsolete sextant biopsy scheme (Hodge et al., 1989). Also thickness of needle was questioned - 18G $(1.27 \mathrm{~mm})$ was compared to thinner needles $(0.9 \mathrm{~mm}$ (20G), $0.8 \mathrm{~mm}$ and $0.7 \mathrm{~mm}(22 \mathrm{G})$ ) - this old study found $0.9 \mathrm{~mm}$ may be acceptable (Norberg et al., 1994) - however it is not used in practice today. More recent studies evaluated thickness of needles again - non-ferromagnetic titanium needles were evaluated for quality of yield in comparison to standard needles - 16G $(1.65 \mathrm{~mm})$ titanium needle was found to provide samples of good quality and better compared to $18 \mathrm{G}$ regular (Franiel et al., 2006). However, also for MRI guided puncture, commercially available product is 18G needle (TSK, Japan) with characteristics comparable to regular needles.

Until recently, only straight needles were in wide use. This creates problem with accessibility (see section 3.2). Recent machine for stereotactic trus biopsy Targetscan aims to overcome this problem with new pliable needle, which bends and allows good approach to most sites in the prostate in side-fire configuration.

\subsection{Image guidance}

In the beginning of transrectal prostate ultrasound era, large efforts were made attempting to recognize cancerous areas of prostate on gray ultrasound picture. Although hypoechoic lesions were identified as important (Terris et al., 1991) and we still lean toward specifically sampling hypoechoic areas as suspect in our every-day prostate biopsy work, we can not rely on them. After color doppler ultrasound was introduced, suspect areas were proposed to be the ones, which have higher or disorganized blood flow. Many studies have confirmed better sampling with the help of doppler or color flow imaging. However, presentation of subtly disorganized prostate vasculature and blood flow in potential cancer foci is very delicate and very dependent on sonographist, so only highly specialized individuals were and are able to put theory into practice. They are still trying to improve visualization of vasculature, either with ultrasound contrast or with other pharmacological agents, but other three presently available imaging techniques seem more promising as they may be more standardized and therefore easier for every urologist or radiologist, who, in a hurry and overwhelmed with other everyday work, perform mass of prostate biopsy burden: elastography, ANNA C-TRUS and HistoScanning.

\subsubsection{Role of MRI}

Magnetic resonance imaging with different modalities has established its role in prostate cancer imaging. Apart from T1 and T2 weighted images (Jager et al., 1996), which are not enough, multi-modal approach, like diffusion weighted imaging and dynamic contrast enhanced imaging was found necessary to identify tumor suspicious regions. Role of endorectal coil, although sometimes debated (for example for 3T may not be so important as 
for 1.5T), seems also well established (Comet-Batlle et al., 2003). Tumor suspicious regions are found in different proportions, depending on criteria and number of different imaging modalities applied and can reach up to $98 \%$ even in post-trus-negative biopsy setting. After tumor suspicious regions are identified, sampling is needed.

The easiest approach would be image fusion to trus picture, which is moving from development phase (Hu et al., 2010) and in some centers already represents routine practice (for example Heidelberg, Germany). Two systems are in development: transrectal Artemis Eigen, Grass Valley, CA, USA (Natarajan et al., 2011) and transperineal BiopSee - MedCom, Darmstadt, Germany (Hadaschik et al., 2011). Incidental reports show identification and confirmation of cancer in patients with previously negative ANNA C-TURS biopsy, however, at present there are no studies which would compare any of the mentioned techniques and show individual strengths and indications.

Some researchers perform MRI examination with plastic simulator of endorectal probe insitu to simulate deformation expected during trus biopsy setting (Ukimura et al., 2010). Others perform 3D ultrasound imaging and use electromagnetic positioning device to perform biopsies (Turkbey et al., 2011).

Straightforward use of MRI would be MRI guided biopsy of MRI identified suspicious regions of prostate. Although at present available only in few institutions, this may very soon become more widespread as technology, procedure and equipment seem more and more ready for prime time (Roethke et al., 2011). Two independent retrospective series, performed with 1.5T or 3T magnets, from Netherlands (Hambrock et al., 2010) and from Germany (Roethke et al., 2011), report 52\% and 58\% (of patients with tumour suspicious regions identified) of positive MRI-guided biopsies after previous negative trus guided prostate biopsies.

\subsubsection{ANNA C-TRUS and HistoScanning}

Idea about reflected ultrasound wave analysis, which should reveal more data than can be seen just with naked eye, is old. There were and are still experiments taking place in developing algorithms of data analysis. Most often prostate is evaluated with transrectal ultrasound before radical prostatectomy and pictures are saved. After radical prostatectomy, histological sections of prostate with known areas of cancer and benign tissue are correlated with saved ultrasound data. Aim is to allow identification of cancer regions on ultrasound before biopsy or surgery. There may be many usages HistoScanning is evaluated for prediction of Gleason score, volume of cancer, number and localization of cancer foci, prediction of location of cancer focus in relation to neurovascular bundle and in relation to prostate borders - all those data may be useful not only for decision to proceed or postpone biopsy and to guide biopsy, but also for preand peri-operative or other treatment planning.

ANNA C-TRUS is a method, which analyzes typical transrectal ultrasound pictures of prostate in transversal plane (for example 5, on sections, where one normally takes biopsy cores). Pictures can be taken with any digital US scanner. Pictures are then sent, uncompressed (using either .tif, .bmp or .png format), using internet, to the provider. After analysis, suspect areas are marked on pictures and urologist repeats examination, this time taking samples from areas marked. All data available about this method seem at present still from the inventor and copyright holder of the technique, prof. Loch from Flensburg, they seem at present not independently evaluated. From author's report in 2010, it seems C-TRUS 
ANNA technique detected 66 cancers, taking up to 6 cores in a series of 132 patients with previous negative prostate biopsy. Series included 62 patients with previous 1 negative biopsy, 41 with previous 2 negative biopsies, 18 with 3 negative biopsies, 6 with 4 negative biopsies and 5 with previous more negative biopsies (5-6) (Loch, 2010). This indicates 50\% positive biopsy in a setting where lower numbers would be obviously expected, but data are not clear which part of the C-TRUS ANNA positive biopsies belongs to group of only one previous negative biopsy, some of them with only 6 cores, and which was percentage in a subgroup of patients with more negative biopsies. Method is commercially available from Fresenius Kabi Deutschland, Bad Homburg and costs in 2010 without tax (VAT) approximately 378 eur per use (one set of pictures analysis - one patient).

Prostatic HistoScanning was developed proprietary by company AMD, Waterloo, Belgium in cooperation with $\mathrm{B} / \mathrm{K}$ ultrasound manufacturer. According to company's web site (accessed in April 2011), it is commercially available in EU and Canada and awaits FDA approval for US. First it was aimed as "triage test for men deemed to be at risk for prostate cancer and who wish to avoid prostate biopsy" (Braeckman et al., 2008). Later it seems they realized getting rid of biopsy is at present not attainable goal and they focused on improving sampling of the prostate at biopsy (Braeckman et al., 2008). It seems method was developed by comparing raw ultrasound data from prostates before biopsy to histological results of patients, positive for cancer, who underwent radical prostatectomy. In this way it seems development was similar to ANNA C-TRUS, each using own mathematical modeling for differentiation between benign and malign areas of prostate. However, AMD's HistoScann uses in a way "more straightforward" data, in a technical sense - but it needs specific $\mathrm{B} / \mathrm{K}$ ultrasound machine and specific probe and is limited regarding other US manufacturer's data. In the community, availability of proper US machines for addition of HistoScann technology is limited. Advantage, compared to C-TRUS ANNA is in data analysis and processing in a "black box", which is for AMD's HistoScanning on site, while with C-TRUS ANNA one has to send data (over internet) to central facility and wait for analysis, therefore ultrasound prostate examination and biopsy can not be performed the same day, while HistoScann allows this. How often algorithms are changed and which are better, has not been evaluated yet although both systems are already commercially available in Europe and are, as such, competitors.

Some specific claims about HistoScanning were challenged in the letter to the editor of BJU (Aigner \& Frauscher, 2009), objecting name of the method and questioning resolution and ability of ultrasound to detect small tumor foci. In response, authors admit some limitations of their method, specifically lower quality of signal and therefore potentially less reliable analysis in case of dense calcifications in the prostate or for analyzing anterior component of a very large prostate. They compare it with MRI claiming there is wider availability or US compared to MRI. It is at present not true - MRI is available in a lot of hospitals, endorectal coils are single use, however, specific B/K ultrasound machine with particular probe and motorized machine for rectal probe guiding and AMD's "black box" are not available and seem at present more costly compared to MRI examination. Advantage of all ultrasound approaches compared to MRI approaches lies in assumption of ultrasound picture to be easier for use in subsequent sample acquisition. With the expected development of programs for US - MRI picture fusion, this advantage of pure-ultrasound approach may disappear. Question which is better or are all those methods (MRI (T-2, DW and spectroscopy), elastography, C-TRUS ANNA and HistoScanning) comparable or perhaps 
they may supplement each other, will become important source of research endeavours in the future. HistoScanning manufacturer intends to use the technology also for other cancers, like ovary, thyroid and breast, which may be advantageous as prostate diagnosis may benefit from multidisciplinary team. On the other side, C-TRUS ANNA was developed by urologists for urologists, can be used in almost any setting (any digital ultrasound machine is good) and seems to have at present more peer reviewed data. HistoScanning is not aiming only towards prostate biopsy guidance, but also aims at other potentially useful predictions regarding prostate cancer and seems to have larger research base with groups from different countries (UK, Germany) who study its potential applications. Whether one or both techniques will stand the test of time and what role they will play remains open.

\subsubsection{Elastography}

Real time transrectal ultrasonoelastograpy of the prostate is aimed at discrimination between harder and softer areas of prostate tissue. MRI elastography technology was also developed (S. Li et al., 2011), but here only ultrasound is described. Back-scattered ultrasound waves are displaced with compression or decompression of tissue (approximately 2\%), harder areas showing less displacement compared to softer (Salomon et al., 2008). Elastography is performed in real-time, at the time of biopsy - no previous transrectal ultrasound examination (as for C-TRUS ANNA) is necessary. By subjectively observing US elastography picture, operator aims at evaluating symmetry of stiffness, focal areas of hardness and persistence of stiffness with probe tilting, aiming at stiff nodule more than $5 \mathrm{~mm}$ in diameter and persistence of stiffness after probe tilting (Giurgiu et al., 2011). There are different scoring systems (Salomon et al., 2009), some focus on identifying smaller lesions and potentially showing increased sensitivity (Kamoi et al., 2008). Technique of elastography is still improving, better differentiation markers are being developed constantly (Zhang et al., 2011). Further, standardization of compression with idea of leaving this part to the machine is also in testing (Tsutsumi et al., 2010). Regarding companies which provide elastography equipment, most studies have been performed using Hitachi machine, which is commercially available for prostate applications and most tested, although other manufacturers also offer this technology. Among target-biopsy techniques elastograpy seems at present most widely spread as technology is also in use for breast cancer (primarily) and investment needed is only in US machine and probe, there are no perinvestigation charges as for C-TRUS ANNA. Elastography procedure is also much simpler compared to MRI-US fusion. Another advantage of elastography is in its compatibility with power/color doppler techniques for image guidance, which can be performed simultaneously, therefore gaining from two sources. There are quite a few published studies describing experience with prostate elastograpy from different parts of the world. Study results are positive and seem to support claims that elastography improves cancer detection rate. One of the very appealing studies, from USA, analyzed help of elastograpy in biopsy of men with PSA values between 1.25 and 4 and free/total PSA ratio less than $18 \%$ (Aigner et al., 2010). They were able to detect $24 \%$ of cancers using 5 cores with elastography guidance compared to $5.1 \%$ cancers using 10 systematic biopsies. Another study, from Romania, used and compared in the same set of patients gray scale, doppler and elastograpyh data (Giurgiu et al., 2011). They found, in a series of 65 patients and $43 \%$ of them with identified cancer on biopsy, sensitivity of elastograpy to be $68 \%$ and specificity $62 \%$. Particularly promising was elastography in a subgroup of older than 70 years, where sensitivity 
increased above $80 \%$ and lead authors to propose, if their results are further confirmed, in case of negative elastography and doppler, biopsy in this group and in relatively stable PSA, may be avoided.

On recent demonstration of C-TRUS ANNA and elastography at the occasion of EAU Congress in Vienna (march 2011), where both techniques were exposed to a patient with 4 previous negative biopsies and rising PSA, both techniques failed to find cancer in those two patients. This shows, as one can deduce from literature cited above: in approximately $50 \%$ of patients with suspicious characteristics (PSA) and previous negative biopsy, we are unable to find cancer at present. For how long? Will they develop cancer in the future? What is the right strategy to follow them? How they end? All those questions are important and need answers in future research.

\subsubsection{Color, power doppler}

Angiogenesis is important in development of cancer and increased vascularity was detected in tumors in general and in radical prostatectomy specimens, therefore use of ultrasound to detect those changes was proposed. Color doppler imaging estimates mean frequency shift of doppler signal to determine velocity and direction of flow. Power doppler shows total energy of the signal by integrating it, therefore resulting in sig nal with homogenous background and more precise detection of smaller and low flow vessels (Remzi et al., 2004). Study of usefulness of power and color doppler for evaluation of hypoechoic lesions showed $80 \%$ sensitivity and $82 \%$ specificity for detecting prostate cancer (Cho et al., 2000). Standardized criteria for scoring different degrees and distributions of prostatic vascularity were developed and also subjective scales seem to work well (Mitterberger et al., 2010), however this points to high subjectivity of the method, which is its drawback.

Power doppler was used for evaluation of peripheral prostatic capsular vessels, parenchymal vessels and vessels anastomosing with extraprostatic vessels (Sauvain et al., 2003). Criteria for suspicion of cancer in this study were increase in number of intra-lesional vessels, disoriented vessels or verticalized vessels in peripheral gland, asymmetrical blood flow, mass effect on the intraprostatic perilesional vessels and vessels in peripheral margins. Analyzing all those criteria, they aimed at estimation of prostate cancer stage by dividing lesions into three groups: absent extracapsular involvement, undetermined extracapsular involvement and presumably present extracapsular involvement. In this series, 55.7\% patients had cancer and sensitivity of power doppler ultrasound was claimed to be $92 \%$, specificity $72 \%$ (compared to $88 \%$ and $58 \%$ for ultrasound only). Group with ultrasound estimated lack of extracapsular involvement had this found in final pathology in $11 \%$, while group with ultrasound suspicious for extracapsular involvement had it confirmed in $87 \%$. Authors (Sauvain et al., 2003) conclude power doppler ultrasound improves accuracy of ultrasound imaging in the diagnosis of cancer, can increase detection rate, optimize number of biopsy cores and also predict extracapsular invasion by identification of capsule perforating vessels.

When using ultrasound for evaluation of minor differences in prostate blood flow between cancerous and benign areas, many factors can interfere with the results - for example position of the patient - it was shown left decubitus position caused flow asymmetry resulting in more biopsies directed toward left side without improving detection rate (Halpern et al., 2002). 
Different pharmaceutical interventions were proposed to increase difference between cancer and benign tissue: improved view with contrast agent, increased flow with phosphodiesterase inhibitor (vardenafil) (Morelli et al., 2011) or decreased flow with 5alpha reductase inhibitor or combination of 5-alpha reductase inhibitor with contrast agent (Mitterberger et al., 2008).

Contrast enhanced transrectal prostate ultrasound was extensively evaluated in multiple research projects (Wink et al., 2008). Microbubbles act as additional reflectors in bloodstream and increase sensitivity of color and power doppler imaging. Newer techniques, for example harmonic imaging, were also tested. Use of ultrasound contrast agent is associated with only minimal side effects, like alterations in taste, flush or pain at the injection site. However, it costs additional money for contrast. It should be performed in 4 minutes after contrast injection (half life of bubbles). Further drawback is strong operator-dependence of the technique. Contrast enhanced ultrasound enables visualisation of prostate cancer (in up to $78 \%$ of cases), but sensitivity and specificity are not enough to avoid systematic biopsies. Targeted biopsies using this technique are claimed to allow lower number of cores per session without decrease in detection rate (Wink et al., 2008).

Use of 5-alpha reductase inhibitor was proposed in two staged approach: first color/power doppler evaluation of prostate is followed by 1-3 week of dutasteride and than reevaluation and biopsy guided to areas, where vascular signals have not decreased after treatment. Additional sextant systematic sample was also taken. Researchers claimed increased yield in targeted cores $(20 \%)$ compared to sextant cores (8\%) (Ives et al., 2005).

\subsection{Biopsy schemes and number of cores}

After finger guided biopsy strategies were replaced with ultrasound guided, it soon became clear (group around dr. Stamey, Stanford) 6 cores, taken in a systematic fashion, finds more cancer than aiming at hypo-echoic areas or randomly (Hodge et al., 1989). Standard approach, which hold for more than 10 years, was established: six cores were taken in parasagittal plane, one at the base, one mid-gland and one at apex. However, patients with negative biopsies and still suspicious for cancer, had repeat biopsies, which were almost as often positive as first biopsy - therefore it was obvious the system was not perfect. Aim should be - perform biopsy - if it is negative, then there is no cancer. Reality was - perform classic sextant scheme biopsy - if it is negative, then there is almost the same probability for cancer as before biopsy. So - search has begun for improvement of systematic biopsy scheme (mainly searching for optimal number of cores and location of cores) and this search has not settled yet. As this text aims at the future, not past, only some examples will be pointed out. Inadequacy of sextant scheme was proven many times, for example (Norberg et al., 1997) and also recent larger and longer retrospective data analyzes still turn to this question, for example regarding sextant biopsy's ability to predict unilateral disease (Mayes et al., 2011). First it became clear biopsies should be directed more laterally in the peripheral zone of the prostate (Eskew et al., 1997). Later, it seemed transitional zone inclusion may improve cancer detection, however this was abandoned for initial biopsy, because of inferior gain from transitional zone directed cores compared to more sampling toward far lateral mid-gland and anterior-apical areas. A lot of cancers are located on anterior horn of prostate. With repeat biopsy, of course, anterior transitional zone is also sampled (Chun et al., 2010). Innumerous analyzes have shown - more cores - more cancer. Prostate size has a role (Taneja, 2006). Nomogram was developed to optimize number of cores needed in relation to prostate size - so called Vienna 
nomogram (Remzi et al., 2005), as it is obvious higher number of cores gives better sampling and improves detection. Later, while some still questioned Vienna nomogram's usefulness (Lecuona \& Heyns, 2010), it became obvious number of biopsy detected cancers is related to sampling density, which is a quotient between prostate size and number of cores taken. A lot of nomograms, which predict probability of positive prostate biopsy, take sampling density into account (Chun et al., 2007). Regarding number of cores, it went up from six at first to eight, later ten, later twelve (a lot of us still using this number at present for majority of patients for first biopsy), fifteen, eighteen... up to twenty-one (Guichard et al., 2007) core per biopsy session. This number seems to be highest present routine extended systematic biopsy scheme, simply because twenty-four or more cores is called saturation biopsy (Ahyai et al., 2010). Many have also argued they were unable to increase their cancer detection rate after increasing number of cores from for example 12 to 18 . This underscores importance not only of number, but also direction of cores.

\subsection{Free hand systematic biopsy, targeted biopsy, prostatic mapping or combination}

Goal of prostate biopsy is not only to find "some" cancer in the prostate, as it was in the past. Now, it has not only to provide representative sample of DIL (dominant intraprostatic lesion), but also to show all "important" cancer areas in the prostate, describe precisely where they are and ensure other regions are cancer free. This is in contrast to efforts of targeted biopsies which claim they may reduce pain and burden of biopsy by reducing number of cores.

Prostate-mapping biopsy approaches, for example TargetScann, have different approach they aim at precisely sampling predefined sections of prostate with larger number of cores. Electronic doppler ultrasound probes are becoming increasingly complex and sensitive to detect blood flow signals in the prostate to help guiding biopsy. TargetScan's device ultrasound probe is sector and at present can not be used for image-guided approaches, but seems to provide relatively reliable results regarding prostate mapping, which is very important for all targeted therapy approaches (Andriole et al., 2007). "Robotic" probes (ultrasound systems, which are just inserted into rectum by physician and then guided by pressing buttons, are being developed also by other manufacturers.

We have therefore a mix of partly competing, some probably complementary and some excluding technologies aiming at improving prostate cancer detection and staging. Which will find its way into every-day practice and to what extent, remains open. It seems at present repeat biopsy yield is about $20 \%-40 \%$ and targeted biopsy methods claim, in repeat, previously negative setting, yield of $50 \%$. All those new approaches need evaluation and confirmation. One way may be showing significantly better performance of targeted or mapping approaches compared to prediction of nomograms for repeat biopsy setting (Chun et al., 2007).

Overall, it seems at present first biopsy should be 10-18 laterally directed cores (depending on prostate size, for prostates larger than $50 \mathrm{ml}$ minimum 14). Targeted biopsy only, with less than 6 cores, may generally not be appropriate for the first biopsy, as it is far from $100 \%$ and we need to assess whole prostate.

For second and later biopsies, as targeted opinions are becoming more and more widespread and therefore accessible and are not untested technical glitches any more, we may in 2011 suggest any of the recently developed opinions, depending on local availability, as follows. 
1. If no targeted approach is available and also there is lack of funds (for example for CTRUS ANNA), transrectal saturation biopsy may be performed and probably it may be useful to perform MRI or choline PET-CT to help identifying suspicious areas.

2. If equipment and local expertise allow, any of the targeted biopsy methods (for example C-TRUS ANNA or others) should be used.

3. Stereotactic biopsy (TargetScan or transperineal) is definitely better opinion compared to free-hand saturation biopsy. Stereotactic approach may also be suggested after diagnosis, regarding watchful waiting or minimally invasive therapies planning.

\section{Periprocedural considerations}

Prostate biopsy is potentially dangerous and painful procedure. Preparation, informed consent with explanation of possible complications, administration of proper antibiotic prophylaxis, policy on anticoagulant and antiaggregation medications and pain management should be standardized and followed in every patient.

\subsection{Enema and needle handling}

Although bowel preparation with enema or clear fluids are not necessary before biopsy (Zaytoun et al., 2011) or no statistically significant increase in complication rate was identified with change of regimen (Ruddick et al., 2011), some still claim less septic complications with enema use (Kanjanawongdeengam et al., 2009) or even with the way enema is properly administrated (Huang et al., 2006). In the light of modern approaches to bowel surgery, extensive enemas really look outdated, but it is obvious rectum should be empty before biopsy and suppository in the evening or morning before biopsy seems very reasonable and appropriate. The future with development of resistant bacteria may even bring back old classical methods (cleaning rectum with povidone iodine enema or simply povidone iodine suppository), but at present this is not standard.

Question of role of re-inserting "dirty" needle. Most of us use one needle for the whole procedure (all cores). Some (Kisner in Maribor, Slovenia) have insisted on using sterilized needle with every core, others studied cleaning needle with povidone iodine solution during procedure (Koc et al., 2010). No decrease in complications was shown with those techniques.

\subsection{Antibiotics}

Most common causative organism for infectious complications following trus prostate biopsy is E.coli. Antibiotic prophylaxis is necessary and guidelines from European and American urological societies have been issued and regulate this question, although different antibiotic regimens are used in practice. Guidelines are freely accessible on web from the issuing societies (EAU and AUA) and provide also extensive lists of literature, which will therefore not be reviewed again here.

EAU guidelines (www.uroweb.org, 2010 edition) recommend antimicrobial prophylaxis, but admit choice of regimens remains debatable. They list studies which suggest single doses for low-risk patients and remark, prolonged course should be considered for high-risk patients. Expected patogens are Enterobacteriaceae and possibly also anaerobes. Recommended antibiotics are fluoroquinolons, TMP+SMX and metronidazole with question mark (no evidence). 
AUA guidelines (www.auanet.org, 2008 edition, reviewed 2010) also confirm prophylaxis is indicated in all patients as randomized controlled trials have confirmed significantly lower rates of complications in antibiotic groups. They also claim single dose may be adequate.

A lot depends on local antibiotic resistance patterns. For example, if TMP+SMX regimen is not used even for non-complicated urinary tract infections in one area, one would not use it for prostate biopsy prophylaxis either. One can never predict for sure future development of antibiotic resistance. Therefore, constant vigilance is needed and monitoring rates of infectious complications is necessary. Special attention should focus on repeat biopsies and this setting may sometimes deserve different antibiotic scheme or previous culture and susceptibility analysis. Later may be performed in two ways - patients with catheters or other urinary tract insertions may be screened using urine culture (Bruyere et al., 2010), but all who need screening should have their stools sample cultured for resistant strains. Resistant strains do occur and may significantly contribute to complications (Liss et al., 2011). Due to high probability of E.coli resistance to quinolones in cases of patients returning to hospital after prostate biopsy with quinolone prophylaxis, it is wise to use another antibiotic before cultures are known (although it seems obvious, people do often get prescribed flouroquinolone again). If there is no or low risk for ESBL, cephalosporines (probably third generation) may be the best initial guess (Zaytoun et al., 2011).

Although single dose is claimed useful, in our and many other situations most patients can be considered not low risk regarding infectious risk classifications (more than 65 years of age, concomitant diseases, like diabetes and lower urinary tract symptoms, incomplete bladder emptying). Therefore typical scheme (as we use it and others, for example (CamposFernandes et al., 2009), uses ciprofloxacin $500 \mathrm{mg}$ twice daily started before biopsy and continued for three days. It was shown to decrease rate of complications after biopsy (Schaeffer et al., 2007). As every single infectious complication, even most minor, requiring any health-service contact, even only consultation, is seen as a big problem and aim is to avoid any complication, there are many patients who probably benefit from short course and not single dose antibiotic and this may be further reason why urologists are reluctant in accepting single dose only approach.

Metronidazol is added in some centers routinely, but most do not use it at present. However, it might be useful for specific patients, with specific predisposing conditions and in combination with other antibiotics (for example cephalosporins, although subjective experience shows more complications with their use for this purpose), when flouroquinolone resistance or intolerance is present.

Instead of 1-2 hour prior to procedure fluoroquinolone orally, same use parenteral aminogylcoside (gentamicin or amikacin) or aminopenicilline with betalactamase inhibitor (co-amoxiclav) at the time of biopsy, which is followed by oral antibiotic (often fluoroquinolone, but also others) at home. This scheme is used in some centers and may be helpful when compliance with oral regimen prior to biopsy is questionable or for allergy and non-tolerance to quinolones or in areas with high resistance to quinolones (Kehinde et al., 2008). Combination of periprocedural oral dose of ciprofloxacine with iv dose of gentamicin may be method of choice for single dose regimens.

Additional important recent problem regarding fluoroquinolones was finding significantly different serum concentrations of active drug comparing different generic manufacturers (Kehinde et al., 2010). Apart from probable reason for higher complication rate, substandard antibiotics preparations also contribute to resistance development as longer courses are needed and as a consequence low concentrations of drug are present in the environment for longer time. 


\subsection{Pain control}

Only $11 \%$ of urologists in US used local anesthesia to reduce pain during trus biopsy in 2002 (Davis et al. 2002). At the time, a strong appeal from one of the most distinguished opinion leaders favored local anesthesia (Soloway, 2003). Thereafter, guidelines (AUA, EAU, NCCN) all recommended or even mandated (AUA) local pain medication use during this procedure. Intrarectal application of eutectic cream or lidocaine jelly may decrease pain as some anesthetic agent may reach site of pain with diffusion, but it is variable and is considered not adequate. Pain during transrectal prostate biopsy is caused by two sources.

First source of pain is probe insertion and presence and movement of probe in the anal canal during biopsy. This can be ameliorated with slow and gentle dilation and local lidocaine jelly or EMLA cream, but other measures for relaxation of sphincter were also used with success and are available - local glyceryl trinitrate oinment or spray or local $2 \%$ diltiazem or $0,2 \%-0,5 \%$ nifedipine oinment. Using gylceryl trinitrate oinment, headache was noted as side effect in $10 \%$ of patients - dose was $2 \mathrm{mg}$ (McCabe et al., 2007). It remains open, whether lower dose of spray $(0,4 \mathrm{mg} /$ activation) would reach same effect with less side effects.

Second source of pain during trus biopsy is related to nerves in prostate capsule and neurovascular bundles. After a lot of research (for example (Scattoni et al., 2010)) it seems accepted injection of $2 \times 5 \mathrm{ml}$ (each side) of 1\% lidocaine most appropriately reduces pain. Site of injection may be at the base (basolateral periprostatic nerve plexus area, described also as prostate-vesicular junction injections) or at the apex. Debate where to inject sill continues. Quality control suggested for standard technique of periprostatic block, observation of hypoechoic nodule ("wheal") formation on the site of injection is needed. It was shown least pain (best effect) was observed, when hypoechoic nodule formed after injection on both sides (Obek et al., 2006). Regarding injectable agents, for potential lidocaine allergic patients, tramadol has significant local anesthetic properties and is universally available and it has also been studied in this setting (Seckiner et al., 2011).

Addition of oral medication, either for sedation or for additional pain relief may be also helpful in selected patients.

\section{Complications}

Generally, complications are: hematuria (13\%-74\%), hemospermia (30\%), blood at stools (1\%), pain (4\%), nausea (up to $1 \%$ ), fever (up to $1 \%$ ), epididymitis (up to $1 \%$ ), infection which needs hospitalization $(0,3 \%)$. Most feared complication is sepsis.

Another important complication is bleeding. Patients can bleed from rectum, they can observe hematuria or hemospermia. Bleeding is most often self limiting and settle in a few days. Rarely significant issues (bladder tamponade or significant rectal bleeding) would occur. Such occasions would of course necessitate hospitalization or use of appropriate standard measurements for treatment. Bleeding may be more significant with anticoagulant treatment. Warfarin is stopped well before biopsy and patient is covered with low molecular weight heparin. Low dose acetylsalicylic acid (aspirin) may be continued, although some still recommend a drug holiday for a few days (till bleeding settles). There are no experience with newer antithrombotic drugs (for example dabigatran and other factor Xa inhibitors) and it is generally suggested to be avoided during prostate biopsy (changed to lowmolecular weight heparin, the same as for warfarin). Clopidogrel should also be stopped, although there is a report claiming $15 \%$ of urologists to continue with both clopidogrel or 
warfarin (Brewster et al., 2010). This is not advisable, except aspirin and low molecular weight haparin, all other similarly working medications should be stopped before biopsy. Regarding clopidogrel, explicit agreement and consent between patient, his cardiologist and urologist may result in exception, but extreme caution is needed.

Immediate complications, like fainting, diaphoresis should be controlled by adequate local pain control. It is also not advisable for patients to be completely fasted.

Rate of complications increases with time. Most important and frequent seem infectious complications. Reasons for increasing rates of complications may be increasing numbers of cores per procedure or increased antibiotic resistance (Nam et al., 2010).

Long term complications of prostate biopsy would be development of pain syndromes or problems with erectile function, which was described recently (Klein et al., 2010). This reminds us that indefinitely repeating biopsies and increasing number of cores per biopsy may not be the best way forward. Selective, targeted approaches must be taken seriously, as prostate biopsy is not without its consequences.

\section{Chemopreventive stategies}

Inhibitors of 5-alpha reductase (5ARI), finasteride or dutasteride, may be used short term to decrease blood flow in the prostate before biopsy (as described at the end of section 3.4.4). Further, it is speculated their longer term use (6 months or more) may decrease proportion of benign prostate in a whole gland and in this way increase chances for prostate cancer detection on prostate biopsy. It may also reduce development of low grade cancer. One possible strategy for use of 5ARI inhibitors is prescription of drug after first or second negative biopsy and then regular follow up of PSA. PSA is expected to decrease. Trigger for repeat biopsy is any increase of PSA above nadir or if PSA value under 5ARI is above $40 \%$ of initial PSA value. Described approach was recently retrospectively evaluated in abstract form, using REDUCE data (Roobol et al., 2011). However, a proportion of prostate cancers do progress (for example on watchful waiting) without this fact reflecting in increase of PSA. Therefore a possibility of prostate cancer progression (in patients on 5ARI treatment or without) while PSA values would not increase is a serious concern and needs further research. We should always be aware, none of our methods is $100 \%$ successful.

\section{Conclusion}

Future of prostate biopsy will be interesting, a lot of new ideas and technologies are competing at present and it remains open which will, in the end, dominate the market and our every-day practice.

Although new targeted technologies, either ultrasound or magnetic resonance, may improve detection and sampling and reduce need for increasing number of cores and repeat biopsy sessions, none seem at present nearing $100 \%$ sensitivity or specificity. At present, approximately $50 \%$ positive biopsy rate is expected in repeat biopsy setting using either CTRUS ANNA or MRI-guided or MRI-US picture fusion guided biopsy.

As burden of biopsies may increase dramatically in the near future (as explained above (Quon et al., 2011)) further increases in complexity and technological demands may not be able to satisfy mass biopsy needs. Prostate biopsy is not very demanding procedure, potential harms and problems for patients do exist, but are not nearly as large as for different forms of prostate cancer treatments. Therefore, such a breakthrough as happened 
in the field of prostate surgery regarding robotic assisted prostatectomy, is not expected. Perhaps we may expect in the near future coexistence of many different biopsy opinions and methods, which are showing comparable results, the same situation as developed for surgical treatment of prostate cancer, where robotic, laparoscopic and open radical prostatectomies progressed to the level, where all show same good results (Eden et al., 2011). It seems present simple system - transrectal probe with 10-20 samples per session, with some additional help of ultrasound picture analysis and systematic sampling systems or not - is here to stay and will be main working horse for enormous number of prostate biopsies which are expected to be performed in the next decade. New markers (PCA3 and p2PSA) will complement PSA and free PSA in decisions about second and further repeat biopsies. At the same time different US and MRI methods, tailored to different patients needs, wishes and different predicted treatment modalities will be available to supplement basic approach when needed and will develop further.

\section{References}

Abdollah, F., Novara, G., Briganti, A., Scattoni, V., Raber, M., Roscigno, M., Suardi, N., et al. (2011). Trans-rectal Versus Trans-Perineal Saturation Rebiopsy of the Prostate: Is There a Difference in Cancer Detection Rate? Urology, 77(4), 921-925.

Ahyai, S. A., Isbarn, H., Karakiewicz, P. I., Chun, F. K. H., Reichert, M., Walz, J., Steuber, T., et al. (2010). The presence of prostate cancer on saturation biopsy can be accurately predicted. BJU Int, 105(5), 636-641.

Aigner, F., \& Frauscher, F. (2009). RE: Computer-aided ultrasonography (HistoScanning): a novel technology for locating and characterizing prostate cancer. BJU Int, 103(1), 115-116.

Aigner, F., Pallwein, L., Junker, D., Schafer, G., Mikuz, G., Pedross, F., Mitterberger, M. J., et al. (2010). Value of real-time elastography targeted biopsy for prostate cancer detection in men with prostate specific antigen $1.25 \mathrm{ng} / \mathrm{ml}$ or greater and 4.00 $\mathrm{ng} / \mathrm{ml}$ or less. J Urol, 184(3), 913-917.

Akhavan, A., Keith, J. D., Bastacky, S. I., Cai, C., Wang, Y., \& Nelson, J. B. (2007). The proportion of cores with high-grade prostatic intraepithelial neoplasia on extendedpattern needle biopsy is significantly associated with prostate cancer on sitedirected repeat biopsy. BJU Int, 99(4), 765-769.

Andriole, G. L., Bullock, T. L., Belani, J. S., Traxel, E., Yan, Y., Bostwick, D. G., \& Humphrey, P. A. (2007). Is There a Better Way to Biopsy the Prostate? Prospects for a Novel Transrectal Systematic Biopsy Approach. Urology, 70(6, Supplement 1), S22-S26.

Andriole, G. L., Grubb, R. L., Buys, S. S., Chia, D., Church, T. R., Fouad, M. N., Gelmann, E. P., et al. (2009). Mortality Results from a Randomized Prostate-Cancer Screening Trial. NEJM, 360(13), 1310-1319.

Auprich, M., van Poppel, H., Marberger, M., Stenzl, Arnulf, Mulders, P. F. A., Huland, Hartwig, Abbou, C.-C., et al. (2011). 2320 Initial and repeat prostate biopsy: comparative peerformance analysis of PSA, \%FPSA, prostate volume and urinary PCA3 including development of novel PCA3 cut-off tresholds. J Urol, 185(4, Supplement 1), e930.

Balk, S. P., Ko, Y.-J., \& Bubley, G. J. (2003). Biology of Prostate-Specific Antigen. JCO, 21(2), $383-391$. 
Bektic, J., Darte, C., Skradski, V., Steiner, E., Schaefer, G., Bartsch, G., Horninger, W., et al. (2010). 985 Access [-2]proPSA and Beckman Coulter prostate health index (PHI) and early detection of aggressive prostate cancers. Eur Urol Supplements, 9(2), 309.

Bektic, J., Carroll, P. R., Cooperberg, M. R., Klocker, H., Steiner, E., Skradski, V., Horninger, W., et al. (2011). 747 The worst cancers send early PSA signals that would allow early detection if monitoring focused on increasing PSA. Eur Urol Supplements, 10(2), 238.

Bill-Axelson, A., Holmberg, Lars, Ruutu, M., Garmo, H., Stark, J. R., Busch, Christer, Nordling, S., et al. (2011). Radical Prostatectomy versus Watchful Waiting in Early Prostate Cancer. NEJM, 364(18), 1708-1717.

Braeckman, J., Autier, P., Garbar, C., Marichal, M. P., Soviany, C., Nir, R., Nir, D., et al. (2008). Computer-aided ultrasonography (HistoScanning): a novel technology for locating and characterizing prostate cancer. BJU Int, 101(3), 293-298.

Braeckman, J., Autier, P., Soviany, C., Nir, R., Nir, D., Michielsen, D., Treurnicht, K., et al. (2008). The accuracy of transrectal ultrasonography supplemented with computeraided ultrasonography for detecting small prostate cancers. BJU Int, 102(11), 15601565.

Brewster, S., Turkeri, L., Brausi, M., Ravery, V., \& Djavan, B. (2010). 5A prospective survey of current prostate biopsy practices among oncological urologists. Can J Urol, 17(2), 5071-5076.

Bruyere, F., d'Arcier, B. F., Boutin, J.-M., \& Haillot, O. (2010). Is urine culture routinely necessary before prostate biopsy? Prostate Cancer Prostatic Dis, 13(3), 260-262.

Bussemakers, M. J., van Bokhoven, A., Verhaegh, G. W., Smit, F. P., Karthaus, H. F., Schalken, J.A., Debruyne, F. M., et al. (1999). DD3: a new prostate-specific gene, highly overexpressed in prostate cancer. Cancer Res, 59(23), 5975-5979.

Campos-Fernandes, J.-L., Bastien, L., Nicolaiew, N., Robert, G., Terry, S., Vacherot, F., Salomon, L., et al. (2009). Prostate cancer detection rate in patients with repeated extended 21-sample needle biopsy. Eur Urol, 55(3), 600-606.

Catalona, W. J., Partin, Alan W., Slawin, K. M., Brawer, M. K., Flanigan, R. C., Patel, A., Richie, J. P., et al. (1998). Use of the Percentage of Free Prostate-Specific Antigen to Enhance Differentiation of Prostate Cancer From Benign Prostatic Disease. JAMA, 279(19), $1542-1547$.

Catalona, W. J., Smith, D. S., Ratliff, T. L., Dodds, K. M., Coplen, D. E., Yuan, J. J. J., Petros, J. A., et al. (1991). Measurement of Prostate-Specific Antigen in Serum as a Screening Test for Prostate Cancer. NEJM, 324(17), 1156-1161.

Ching, C. B., Moussa, A. S., Li, J., Lane, B. R., Zippe, C., \& Jones, J. S. (2009). Does transrectal ultrasound probe configuration really matter? End fire versus side fire probe prostate cancer detection rates. J Urol, 181(5), 2077-2082.

Cho, J. Y., Kim, S. H., \& Lee, S. E. (2000). Peripheral hypoechoic lesions of the prostate: evaluation with color and power Doppler ultrasound. Eur Urol, 37(4), 443-448.

Chun, F. K.-H., Briganti, A., Graefen, Markus, Porter, C., Montorsi, F., Haese, A., Scattoni, V., et al. (2007). Development and external validation of an extended repeat biopsy nomogram. J Urol, 177(2), 510-515.

Chun, F. K.-H., Epstein, J. I., Ficarra, V., Freedland, S. J., Montironi, R., Montorsi, F., Shariat, S. F., et al. (2010). Optimizing performance and interpretation of prostate biopsy: a critical analysis of the literature. Eur Urol, 58(6), 851-864. 
Comet-Batlle, J., Vilanova-Busquets, J. C., Saladie-Roig, J. M., Gelabert-Mas, A., \& BarceloVidal, C. (2003). The value of endorectal MRI in the early diagnosis of prostate cancer. Eur Urol, 44(2), 201-207.

Crawford, E. D., Grubb, R., Black, A., Andriole, G. L., Chen, M.-H., Izmirlian, G., Berg, C. D., et al. (2011). Comorbidity and mortality results from a randomized prostate cancer screening trial. J Clin Oncol, 29(4), 355-361.

Davis, M., Sofer, M., Kim, S. S., \& Soloway, M. S. (2002). The procedure of transrectal ultrasound guided biopsy of the prostate: a survey of patient preparation and biopsy technique. J Urol, 167(2 Pt 1), 566-570.

Dite, G. S., Whittemore, A. S., Knight, J. A., John, E. M., Milne, R. L., Andrulis, I. L., Southey, M. C., et al. (2010). Increased cancer risks for relatives of very early-onset breast cancer cases with and without BRCA1 and BRCA2 mutations. Br J Cancer, 103(7), 1103-1108.

Dogan, H. S., Eskicorapci, S. Y., Ertoy-Baydar, D., Akdogan, B., Gunay, L. M., \& Ozen, H. (2005). Can we obtain better specimens with an end-cutting prostatic biopsy device? Eur Urol, 47(3), 297-301.

Eden, C. G., Arora, A., \& Hutton, A. (2011). Cancer Control, Continence, and Potency After Laparoscopic Radical Prostatectomy Beyond the Learning and Discovery Curves. J Endourol. 25(5), 815-819.

Eskew, L. A., Bare, R. L., \& McCullough, D. L. (1997). Systematic 5 region prostate biopsy is superior to sextant method for diagnosing carcinoma of the prostate. J Urol, 157(1), 199-202.

Fink, K. G., Hutarew, G., Pytel, A., \& Schmeller, N. T. (2005). Prostate biopsy outcome using $29 \mathrm{~mm}$ cutting length. Urol Int, 75(3), 209-212.

Franiel, T., Fritzsche, F., Staack, A., Rost, J., Hamm, B., \& Beyersdorff, D. (2006). [Histopathologic quality of prostate core biopsy specimens: comparison of an MRcompatible biopsy needle and a ferromagnetic biopsy needle used for ultrasoundguided prostate biopsy]. Rofo, 178(12), 1212-1218.

Galosi, A. B., Tiroli, M., Cantoro, D., Conti, A., \& Muzzonigro, G. (2010). Biopsy of the anterior prostate gland: technique with end-fire transrectal ultrasound. Arch Ital Urol Androl, 82(4), 248-252.

Giurgiu, C. R., Manea, C., Crisan, N., Bungardean, C., Coman, I., \& Dudea, S. M. (2011). Realtime sonoelastography in the diagnosis of prostate cancer. Med Ultrason, 13(1), 5-9.

Gosselaar, C., Roobol, Monique J., Roemeling, S., \& Schroder, Fritz H. (2008). The Role of the Digital Rectal Examination in Subsequent Screening Visits in the European Randomized Study of Screening for Prostate Cancer (ERSPC), Rotterdam. Eur Urol, 54(3), 581-588.

Guazzoni, G., Nava, L., Lazzeri, M., Scattoni, V., Lughezzani, G., Maccagnano, C., Dorigatti, F., et al. (2011). Prostate-Specific Antigen (PSA) Isoform p2PSA Significantly Improves the Prediction of Prostate Cancer at Initial Extended Prostate Biopsies in Patients with Total PSA Between 2.0 and $10 \mathrm{ng} / \mathrm{ml}$ : Results of a Prospective Study in a Clinical Setting. Eur Urol, In Press, doi: 10.1016/j.eururo.2011.03.052

Guichard, G., Larre, S., Gallina, A., Lazar, A., Faucon, H., Chemama, S., Allory, Y., et al. (2007). Extended 21-sample needle biopsy protocol for diagnosis of prostate cancer in 1000 consecutive patients. Eur Urol, 52(2), 430-435. 
Gustafsson, O., Norming, U., Nyman, C. R., \& Ohstrom, M. (1990). Complications following combined transrectal aspiration and core biopsy of the prostate. Scand J Urol Nephrol, 24(4), 249-251.

Hadaschik, B., Kuru, T., Tulea, C., Teber, D., Huber, J., Popeneciu, V., Pahernik, S., et al. (2011). 2304 Stereotactic prostate biopsy with pre-interventional MRI and live US fusion. J Urol 185(4, Supplement 1), e924.

Halpern, E. J., Frauscher, Ferdinand, Forsberg, F., Strup, S. E., Nazarian, L. N., O'Kane, P., \& Gomella, L. G. (2002). High-frequency Doppler US of the prostate: effect of patient position. Radiology, 222(3), 634-639.

Hambrock, T., Somford, D. M., Hoeks, C., Bouwense, S. A. W., Huisman, H., Yakar, D., van Oort, I. M., et al. (2010). Magnetic resonance imaging guided prostate biopsy in men with repeat negative biopsies and increased prostate specific antigen. J Urol, 183(2), 520-527.

Hara, R., Jo, Y., Fujii, T., Kondo, N., Yokoyoma, T., Miyaji, Y., \& Nagai, A. (2008). Optimal approach for prostate cancer detection as initial biopsy: prospective randomized study comparing transperineal versus transrectal systematic 12-core biopsy. Urology, 71(2), 191-195.

Hodge, K. K., McNeal, J. E., Terris, M. K., \& Stamey, T. A. (1989). Random systematic versus directed ultrasound guided transrectal core biopsies of the prostate. J Urol, 142(1), 71-74.

Hu, Y., Ahmed, H. U., Taylor, Z., Allen, C., Emberton, M., Hawkes, D., \& Barratt, D. (2010). MR to ultrasound registration for image-guided prostate interventions. Medical Image Analysis, In Press, doi: DOI: 10.1016/j.media.2010.11.003

Huang, Y.-C., Ho, D.-R., Wu, C.-F., Shee, J.-J., Lin, W.-Y., \& Chen, C.-S. (2006). Modified bowel preparation to reduce infection after prostate biopsy. Chang Gung Med J, 29(4), 395-400.

Isharwal, S., Makarov, D. V., Sokoll, L. J., Landis, P., Marlow, C., Epstein, J. I., Partin, Alan W., et al. (2011). ProPSA and Diagnostic Biopsy Tissue DNA Content Combination Improves Accuracy to Predict Need for Prostate Cancer Treatment Among Men Enrolled in an Active Surveillance Program. Urology, 77(3), 763-763.

Ives, E. P., Gomella, L. G., \& Halpern, E. J. (2005). Effect of dutasteride therapy on Doppler US evaluation of prostate: preliminary results. Radiology, 237(1), 197-201.

Izmirlian, G., Crawford, E. D., Grub III, R., Hsing, A., Kramer, B. S., Church, T. R., Riley, T. M., et al. (2011). 333 Family history of various cancers and the risk of incident prostate cancer in the PLCO trial. J Urol 185(4, Supplement 1), e134-e135.

Jager, G. J., Ruijter, E. T., van de Kaa, C. A., de la Rosette, J. J., Oosterhof, G. O., Thornbury, J. R., \& Barentsz, J.O. (1996). Local staging of prostate cancer with endorectal MR imaging: correlation with histopathology. Am J Roentgenol, 166(4), 845-852.

Jemal, A., Siegel, R., Xu, J., \& Ward, E. (2010). Cancer statistics, 2010. CA Cancer J Clin, 60(5), 277-300.

Jemal, A., Bray, F., Center, M. M., Ferlay, J., Ward, E., \& Forman, D. (2011). Global cancer statistics. CA Cancer J Clin, 61(2), 69-90.

Kamoi, K., Okihara, K., Ochiai, A., Ukimura, O., Mizutani, Y., Kawauchi, A., \& Miki, T. (2008). The utility of transrectal real-time elastography in the diagnosis of prostate cancer. Ultrasound Med Biol, 34(7), 1025-1032. 
Kanjanawongdeengam, P., Viseshsindh, W., Santanirand, P., Prathombutr, P., \& Nilkulwattana, S. (2009). Reduction in bacteremia rates after rectum sterilization before transrectal, ultrasound-guided prostate biopsy: a randomized controlled trial. J Med Assoc Thai, 92(12), 1621-1626.

Kawakami, S., Okuno, T., Yonese, J., Igari, T., Arai, G., Fujii, Y., Kageyama, Y., et al. (2007). Optimal sampling sites for repeat prostate biopsy: a recursive partitioning analysis of three-dimensional 26-core systematic biopsy. Eur Urol, 51(3), 675-682.

Kehinde, E. O., Sheikh, M., Anim, J., Al-Maghrebi, M., Hussein, A. Y., \& John, J. S. (2008). Addition of single dose amikacin to prophylactic quinolones significantly reduces infectious complications of transrectal ultrasound guided biopsy of the prostate gland. J Urol, 179(4, Supplement 1), 717-718.

Kehinde, E., Abdel-Hamid, M., Philips, O., Sharaf, L., \& Babu, A. (2010). 811 A comparative pharmacokinetic study of seven brands of ciprofloxacin in NZW rabbits using liquid chromatography mass spectrometry technique. J Urol, 183(4, Supplement 1), e316-e317.

Klein, T., Palisaar, R. J., Holz, A., Brock, M., Noldus, J., \& Hinkel, A. (2010). The impact of prostate biopsy and periprostatic nerve block on erectile and voiding function: a prospective study. J Urol, 184(4), 1447-1452.

Koc, G., Un, S., Filiz, D. N., Akbay, K., \& Yilmaz, Y. (2010). Does washing the biopsy needle with povidone-iodine have an effect on infection rates after transrectal prostate needle biopsy? Urol Int, 85(2), 147-151.

Kotb, A. F., Tanguay, S., Luz, M. A., Kassouf, W., \& Aprikian, A. G. (2011). Relationship between initial PSA density with future PSA kinetics and repeat biopsies in men with prostate cancer on active surveillance. Prostate Cancer Prostatic Dis, 14(1), 53-57.

Lecuona, A., \& Heyns, C. F. (2010). A prospective, randomized trial comparing the Vienna nomogram to an eight-core prostate biopsy protocol. BJU Int. In Press. doi: 10.1111/j.1465-410X.2010.09887.x.

Li, S., Chen, M., Wang, W., Zhao, W., Wang, J., Zhao, X., \& Zhou, C. (2011). A feasibility study of MR elastography in the diagnosis of prostate cancer at 3.0T. Acta Radiol, 52(3), 354-358.

Liss, M. A., Chang, A., Santos, R., Nakama-Peeples, A., Peterson, E. M., Osann, K., Billimek, J., et al. (2011). Prevalence and Significance of Fluoroquinolone Resistant Escherichia coli in Patients Undergoing Transrectal Ultrasound Guided Prostate Needle Biopsy. J Urol, 185(4), 1283-1288.

Loch, T. (2010). [Core needle biopsy twice negative with rising PSA level. Does imaging help?]. Urologe A, 49(3), 369-375.

Makarov, D. V., Isharwal, S., Sokoll, L. J., Landis, P., Marlow, C., Epstein, J. I., Partin, Alan W., et al. (2009). Pro-Prostate-Specific Antigen Measurements in Serum and Tissue Are Associated with Treatment Necessity among Men Enrolled in Expectant Management for Prostate Cancer. Clinical Cancer Research, 15(23), 7316 -7321.

Malvezzi, M., Arfe, A., Bertuccio, P., Levi, F., La Vecchia, C., \& Negri, E. (2011). European cancer mortality predictions for the year 2011. Ann Oncol, 22(4), 947-956.

Mayes, J. M., Mouraviev, V., Sun, L., Tsivian, M., Madden, J. F., \& Polascik, T. J. (2011). Can the conventional sextant prostate biopsy accurately predict unilateral prostate cancer in low-risk, localized, prostate cancer? Urol Oncol, 29(2), 166-170. 
McCabe, J. E., Hanchanale, V. S., Philip, J., \& Javle, P. M. (2007). A randomized controlled trial of topical glyceryl trinitrate before transrectal ultrasonography-guided biopsy of the prostate. BJU Int, 100(3), 536-538.

Megwalu, I. I., Ferguson, G. G., Wei, J. T., Mouraviev, V., Polascik, T. J., Taneja, S., Black, L., et al. (2008). Evaluation of a novel precision template-guided biopsy system for detecting prostate cancer. BJU Int, 102(5), 546-550.

Miettinen, O. S. (2010). Screening for a cancer: thinking before rethinking. Eur J Epidemiol, 25(6), 365-374.

Mitterberger, M., Aigner, Friedrich, Pinggera, G. M., Steiner, Eberhard, Rehder, P., Ulmer, H., Halpern, E. J., et al. (2010). Contrast-enhanced colour Doppler-targeted prostate biopsy: correlation of a subjective blood-flow rating scale with the histopathological outcome of the biopsy. BJU Int, 106(9), 1315-1318.

Mitterberger, M., Pinggera, G., Horninger, Wolfgang, Strasser, H., Halpern, E., Pallwein, Leo, Gradl, J., et al. (2008). Dutasteride prior to contrast-enhanced colour Doppler ultrasound prostate biopsy increases prostate cancer detection. Eur Urol, 53(1), 112117.

Morelli, G., Pagni, R., Mariani, C., Minervini, R., Morelli, A., Gori, F., Ferdeghini, E. M., et al. (2011). Results of Vardenafil Mediated Power Doppler Ultrasound, Contrast Enhanced Ultrasound and Systematic Random Biopsies to Detect Prostate Cancer. J Urol, 185(6): 2126-2131.

Morgan, T. O., Jacobsen, S. J., McCarthy, W. F., Jacobson, D. J., McLeod, D. G., \& Moul, J. W. (1996). Age-Specific Reference Ranges for Serum Prostate-Specific Antigen in Black Men. NEJM, 335(5), 304-310.

Nam, R. K., Saskin, R., Lee, Y., Liu, Y., Law, C., Klotz, L. H., Loblaw, D. A., et al. (2010). Increasing hospital admission rates for urological complications after transrectal ultrasound guided prostate biopsy. J Urol, 183(3), 963-968.

Natarajan, S., Marks, L. S., Margolis, D. J. A., Huang, J., Macairan, M. L., Lieu, P., \& Fenster, A. (2011). Clinical application of a 3D ultrasound-guided prostate biopsy system. Urol Oncol, 29(3), 334-342.

Ngo, T. C., Turnbull, B. B., Lavori, P. W., \& Presti Jr., J. C. (2011). The Prostate Cancer Risk Calculator From the Prostate Cancer Prevention Trial Underestimates the Risk of High Grade Cancer in Contemporary Referral Patients. J Urol, 185(2), 483-488.

Nieder, C., Norum, J., \& Geinitz, H. (2011). Impact of Common Medications on Serum Total Prostate-specific Antigen Levels and Risk Group Assignment in Patients with Prostate Cancer. Anticancer Research, 31(5), 1735 -1739.

Norberg, M., Busch, C., Stavinoha, J., Scardino, P.T., \& Magnusson, A. (1994). Transrectal ultrasound-guided core biopsies of the prostate. A comparison between the standard 1.2-mm needle and three thinner needles. Acta Radiol, 35(5), 463-467.

Norberg, M., Egevad, L., Holmberg, L., Sparen, P., Norlen, B. J., \& Busch, C. (1997). The sextant protocol for ultrasound-guided core biopsies of the prostate underestimates the presence of cancer. Urology, 50(4), 562-566.

Obek, C., Ozkan, B., Tunc, B., \& Can, G. (2006). Hypoechoic space formation with periprostatic nerve block: myth or reality? Urol Int, 76(3), 236-239.

Oberaigner, W., Horninger, Wolfgang, Klocker, Helmut, Schonitzer, D., Stuhlinger, W., \& Bartsch, Georg. (2006). Reduction of prostate cancer mortality in Tyrol, Austria, after introduction of prostate-specific antigen testing. Am J Epidemiol, 164(4), 376-384. 
Oliveira, M., Marques, V., Carvalho, A. P., \& Santos, A. (2011). Head-to-head comparison of two online nomograms for prostate biopsy outcome prediction. BJU Int, 107(11), 1780-1783.

Pandha, H., Ismail, M., Boxall, A., Bhatt, A., Langley, S., Hindley, R., \& Morgan, R. (2011). 2326 Engrailed-2 (EN2): a urinary biomarker for the diagnosis of prostate cancer without DRE. J Urol, 185(4, Supplement 1), e932-e933.

Pater, L. E., Hart, K. W., Blonigen, B. J., Lindsell, C. J., \& Barrett, W. L. (2011). Relationship Between Prostate-specific Antigen, Age, and Body Mass Index in a Prostate Cancer Screening Population. American Journal of Clinical Oncology, In Press.

Paul, R., Korzinek, C., Necknig, U., Niesel, T., Alschibaja, M., Leyh, H., \& Hartung, R. (2004). Influence of transrectal ultrasound probe on prostate cancer detection in transrectal ultrasound-guided sextant biopsy of prostate. Urology, 64(3), 532-536.

Pepe, P., Candiano, G., Fraggetta, F., Galia, A., Grasso, G., Allegro, R., \& Aragona, F. (2009). Is PSA density still useful in diagnosing prostate cancer? Arch Ital Urol Androl, 81(4), 199-202.

Potter, S. R., \& Partin, A.W. (2000). Hereditary and familial prostate cancer: biologic aggressiveness and recurrence. Rev Urol, 2(1), 35-36.

Quiles, M. T., Arbos, M. A., de Torres, I. M., Blazquez, C., Bastaros, J. M., Placer, J., Doll, A., et al. (2011). 2321 Comparative analysis of prostate cancer antigen 3 mRNA expression in benign peripheral prostatic tissue, cancer and isolated or cancerassociated high grade prostatic intraepithelial neoplasia. J Urol, 185(4, Supplement 1), e930-e931.

Quon, H., Loblaw, A., \& Nam, R. (2011). Dramatic increase in prostate cancer cases by 2021. BJU Int. In Press. doi: 10.1111/j.1464-410X.2011.10197.

Remzi, M., Dobrovits, M., Reissigl, A., Ravery, V., Waldert, Mattias, Wiunig, C., Fong, Y. K., et al. (2004). Can Power Doppler Enhanced Transrectal Ultrasound Guided Biopsy Improve Prostate Cancer Detection on First and Repeat Prostate Biopsy? Eur Urol, 46(4), 451-456.

Remzi, M., Fong, Y. K., Dobrovits, M., Anagnostou, T., Seitz, C., Waldert, Matthias, Harik, M., et al. (2005). The Vienna nomogram: validation of a novel biopsy strategy defining the optimal number of cores based on patient age and total prostate volume. J Urol, 174(4 Pt 1), 1256-1260.

Roethke, M., Anastasiadis, A. G., Lichy, M., Werner, M., Wagner, P., Kruck, S., Claussen, C. D., et al. (2011). MRI-guided prostate biopsy detects clinically significant cancer: analysis of a cohort of 100 patients after previous negative TRUS biopsy. World J Urol. In Press doi: 10.1007/s00345-011-0675-2.

Roobol, M.J., Van Leeuwen, P. J., \& Schroder, F.H. (2011). 19 Combining screening and chemoprevention of prostate cancer. Eur Urol Supplements, 10(2), 34.

Ruddick, F., Sanders, P., Bicknell, S. G., \& Crofts, P. (2011). Sepsis rates after ultrasoundguided prostate biopsy using a bowel preparation protocol in a community hospital. J Ultrasound Med, 30(2), 213-216.

Sakura, M., Kawakami, S., Ishioka, J., Fujii, Y., Yamamoto, S., Iwai, A., Numao, N., et al. (2011). A novel repeat biopsy nomogram based on three-dimensional extended biopsy. Urology, 77(4), 915-920. 
Salomon, G., Graefen, M., Heinzer, H., Huland, H., Pallwein, L., Aigner, F., \& Frauscher, F. (2009). [The value of real-time elastography in the diagnosis of prostate cancer]. Urologe A, 48(6), 628-636.

Salomon, Georg, Kollerman, J., Thederan, I., Chun, F. K. H., Budaus, L., Schlomm, T., Isbarn, H., et al. (2008). Evaluation of prostate cancer detection with ultrasound real-time elastography: a comparison with step section pathological analysis after radical prostatectomy. Eur Urol, 54(6), 1354-1362.

Sauvain, J. L., Palascak, P., Bourscheid, D., Chabi, C., Atassi, A., Bremon, J. M., \& Palascak, R. (2003). Value of Power Doppler and 3D Vascular Sonography as a Method for Diagnosis and Staging of Prostate Cancer. Eur Urol, 44(1), 21-31.

Scattoni, V., Maccagnano, C., Zanni, G., Angiolilli, D., Raber, M., Roscigno, M., Rigatti, P., et al. (2010). Is extended and saturation biopsy necessary? Int J Urol, 17(5), 432-447.

Schaeffer, A. J., Montorsi, F., Scattoni, V., Perroncel, R., Song, J., Haverstock, D. C., \& Pertel, P. E. (2007). Comparison of a 3-day with a 1-day regimen of an extended-release formulation of ciprofloxacin as antimicrobial prophylaxis for patients undergoing transrectal needle biopsy of the prostate. BJU Int, 100(1), 51-57.

Schoenfield, L., Jones, J. S., Zippe, C. D., Reuther, A. M., Klein, E., Zhou, M., \& MagiGalluzzi, C. (2007). The incidence of high-grade prostatic intraepithelial neoplasia and atypical glands suspicious for carcinoma on first-time saturation needle biopsy, and the subsequent risk of cancer. BJU International, 99(4), 770-774.

Schroder, F.H., van der Maas, P., Beemsterboer, P., Kruger, A. B., Hoedemaeker, R., Rietbergen, J., \& Kranse, R. (1998). Evaluation of the digital rectal examination as a screening test for prostate cancer. Rotterdam section of the European Randomized Study of Screening for Prostate Cancer. J Natl Cancer Inst, 90(23), 1817-1823.

Schröder, F. H., Hugosson, J., Roobol, Monique J., Tammela, T. L. J., Ciatto, S., Nelen, V., Kwiatkowski, M., et al. (2009). Screening and Prostate-Cancer Mortality in a Randomized European Study. NEJM, 360(13), 1320-1328.

Seckiner, I., Sen, H., Erturhan, S., \& Yagci, F. (2011). A Prospective, Randomized Controlled Study Comparing Lidocaine and Tramadol in Periprostatic Nerve Blockage for Transrectal Ultrasound-guided Prostate Biopsy. Urology, In Press, doi: 10.1016/j.urology.2011.03.010.

Shikanov, S., Jayram, G., McGuire, M. S., \& Brendler, C. B. (2011). 2322 PCA3 variability in men with very low risk prostate cancer. J Urol, 185(4, Supplement 1), e931.

Soloway, M. S. (2003). Do unto others - why I would want anesthesia for my prostate biopsy. Urology, 62(6), 973-975.

Taneja, S. S. (2006). Prostate biopsy: targeting cancer for detection and therapy. Rev Urol, 8(4), 173-182.

Tang, P., Du, W., Xie, K., Fu, J., Chen, H., Yang, W., \& Moul, J. W. (2011). Characteristics of baseline PSA and PSA velocity in young men without prostate cancer: Racial differences. The Prostate, In Press. doi:10.1002/pros.21418

Terris, M. K., Freiha, F. S., McNeal, J. E., \& Stamey, T. A. (1991). Efficacy of transrectal ultrasound for identification of clinically undetected prostate cancer. J Urol, 146(1), 78-83.

Thompson, I. M., Pauler, D. K., Goodman, P. J., Tangen, C. M., Lucia, M. S., Parnes, H. L., Minasian, L. M., et al. (2004). Prevalence of Prostate Cancer among Men with a Prostate-Specific Antigen Level $\leq 4.0$ ng per Milliliter. NEJM, 350(22), 2239-2246. 
Tsutsumi, M., Miyagawa, T., Matsumura, T., Endo, T., Kandori, S., Shimokama, T., \& Ishikawa, S. (2010). Real-time balloon inflation elastography for prostate cancer detection and initial evaluation of clinicopathologic analysis. AJR Am J Roentgenol, 194(6), 471-476.

Turkbey, B., Xu, S., Kruecker, J., Locklin, J., Pang, Y., Bernardo, M., Merino, M. J., et al. (2011). Documenting the location of prostate biopsies with image fusion. BJU Int, 107(1), 53-57.

Ukimura, O., Hirahara, N., Fujihara, A., Yamada, T., Iwata, T., Kamoi, K., Okihara, K., et al. (2010). Technique for a hybrid system of real-time transrectal ultrasound with preoperative magnetic resonance imaging in the guidance of targeted prostate biopsy. Int J Urol, 17(10), 890-893.

Vickers, A. J., \& Cronin, A. M. (2010). Everything You Always Wanted to Know About Evaluating Prediction Models (But Were Too Afraid to Ask). Urology, 76(6), 12981301.

Vickers, A. J., Till, C., Tangen, C. M., Lilja, H., \& Thompson, I. M. (2011). An Empirical Evaluation of Guidelines on Prostate-specific Antigen Velocity in Prostate Cancer Detection. Journal of the National Cancer Institute, 103(6), 462 -469.

Vlaeminck-Guillem, V., Devonec, M., Colombel, M., Rodriguez-Lafrasse, C., DecaussinPetrucci, M., \& Ruffion, A. (2011). Urinary PCA3 score predicts prostate cancer multifocality. J Urol, 185(4), 1234-1239.

Wink, M., Frauscher, Ferdinand, Cosgrove, D., Chapelon, J.-Y., Palwein, L., Mitterberger, M., Harvey, C., et al. (2008). Contrast-Enhanced Ultrasound and Prostate Cancer; A Multicentre European Research Coordination Project. Eur Urol, 54(5), 982-993.

Yossepowitch, O. (2008). Digital Rectal Examination Remains an Important Screening Tool for Prostate Cancer. Eur Urol, 54(3), 483-484.

Zaytoun, O. M., Anil, T., Moussa, A. S., Jianbo, L., Fareed, K., \& Jones, J. S. (2011). Morbidity of prostate biopsy after simplified versus complex preparation protocols: assessment of risk factors. Urology, 77(4), 910-914.

Zaytoun, O. M., Vargo, E. H., Rajan, R., Berglund, R., Gordon, S., \& Jones, J. S. (2011). Emergence of Fluoroquinolone-resistant Escherichia coli as Cause of Postprostate Biopsy Infection: Implications for Prophylaxis and Treatment. Urology. In Press doi: 10.1016/j.urology.2010.12.067.

Zeegers, M. P. A., Jellema, A., \& Ostrer, H. (2003). Empiric risk of prostate carcinoma for relatives of patients with prostate carcinoma: a meta-analysis. Cancer, 97(8), 18941903.

Zhang, Y., Tang, J., Li, Y.-M., Fei, X., Lv, F.-Q., He, E.-H., Li, Q.-Y., et al. (2011). Differentiation of prostate cancer from benign lesions using strain index of transrectal real-time tissue elastography. Eur $J$ Radiol. In Press doi: 10.1016/j.ejrad.2011.02.037. 


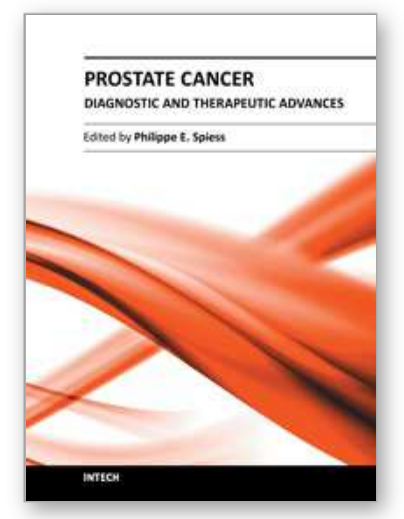

\author{
Prostate Cancer - Diagnostic and Therapeutic Advances \\ Edited by Dr. Philippe E. Spiess
}

ISBN 978-953-307-319-4

Hard cover, 378 pages

Publisher InTech

Published online 25, November, 2011

Published in print edition November, 2011

In this book entitled "Prostate Cancer - Diagnostic and Therapeutic Advances", we highlight many of the significant advances made in our treatment armamentarium of prostate cancer. The book is subdivided into four sections termed: 1) novel diagnostic approaches, 2) surgical treatments options, 3) radiation therapy and its potential sequelae, and 4) medical management and its treatment complications. After reading the present book, readers will be very familiar with the major clinical advances made in our multifaceted treatment approach to prostate cancer over the past decade. This book is a tribute to our pioneering urologists and allied healthcare professionals who have continually pushed forward our traditional therapeutic envelope.

\title{
How to reference
}

In order to correctly reference this scholarly work, feel free to copy and paste the following:

Tine Hajdinjak (2011). Future of Prostate Biopsy: Who Will Get It and How?, Prostate Cancer - Diagnostic and Therapeutic Advances, Dr. Philippe E. Spiess (Ed.), ISBN: 978-953-307-319-4, InTech, Available from: http://www.intechopen.com/books/prostate-cancer-diagnostic-and-therapeutic-advances/future-of-prostatebiopsy-who-will-get-it-and-how-

\section{INTECH}

open science | open minds

\section{InTech Europe}

University Campus STeP Ri Slavka Krautzeka 83/A 51000 Rijeka, Croatia Phone: +385 (51) 770447

Fax: +385 (51) 686166 www.intechopen.com

\section{InTech China}

Unit 405, Office Block, Hotel Equatorial Shanghai No.65, Yan An Road (West), Shanghai, 200040, China 中国上海市延安西路65号上海国际贵都大饭店办公楼405单元 Phone: +86-21-62489820

Fax: $+86-21-62489821$ 
(C) 2011 The Author(s). Licensee IntechOpen. This is an open access article distributed under the terms of the Creative Commons Attribution 3.0 License, which permits unrestricted use, distribution, and reproduction in any medium, provided the original work is properly cited. 